\title{
A NEW CO 2D FE MODEL BASED ON IMPROVED HIGHER ORDER ZIGZAG THEORY FOR THE ANALYSIS OF SOFT CORE SANDWICH PLATE
}

\author{
R.P. KHANDELWAL ${ }^{*}$, A. CHAKRABARTI and P. BHARGAVA \\ Department of Civil Engineering \\ Indian Institute of Technology Roorkee \\ Roorkee-247667, INDIA \\ E-mail: ravi.iitdelhi@gmail.com
}

\begin{abstract}
An efficient $C^{0}$ continuous finite element (FE) model is developed based on a combined theory (refine higher order shear deformation theory (RHSDT) and least square error (LSE) method) for the static analysis of a soft core sandwich plate. In this (RHSDT) theory, the in-plane displacement field for the face sheets and the core is obtained by superposing a global cubically varying displacement field on a zig-zag linearly varying displacement field with a different slope in each layer. The transverse displacement assumes to have a quadratic variation within the core and it remains constant in the faces beyond the core. The proposed model satisfies the condition of transverse shear stress continuity at the layer interfaces and the zero transverse shear stress condition at the top and bottom of the sandwich plate. The nodal field variables are chosen in an efficient manner to circumvent the problem of $C^{l}$ continuity requirement of the transverse displacements. In order to calculate the accurate through thickness transverse stresses variation, the Least Square Error (LSE) method has been used at the post processing stage. The proposed combined model (RHSDT and LSE) is implemented to analyze the laminated composites and sandwich plates. Many new results are also presented which should be useful for future research.
\end{abstract}

Key words: composites, finite element methods, plates, soft-core sandwich.

\section{Introduction}

Composite and sandwich laminates are widely used in civil engineering, aerospace, automotive industry, submarines and other engineering fields due to their advantage of high stiffness and strength to weight ratio. A sandwich construction is a special type of laminated structure having a low strength core and high strength face sheets in the form of composite laminates. Laminated composite (e.g., GFRP, CFRP etc.) structures are weak in shear due to their low shear modulus compared to extensional rigidity. Thus the effect of shear deformation is quite significant which may lead to failure and it becomes more complex in the case of sandwich construction, as the material property variation is very large between the core and face layers.

For reliable and safe designs, it is necessary to understand well the structural behavior of laminated composite and sandwich plates. So it is necessary to develop appropriate computational models for accurately predicting the responses of these laminated sandwich structures. In this context, a number of theories have been developed for accurate modeling of the shear deformation in a refined manner. The Classical Plate Theory (Reissner, 1944) under-predicts displacements and over-predicts the natural frequencies and the buckling loads. However, this kind of approach is not sufficient for laminated plates due to neglecting the transverse shear deformation in the laminates.

Based on their assumed displacement fields, these plate theories can be grouped as: (1) single layer plate theory and (2) layer-wise plate theory. In the single layer plate theory, the deformation of the plate is expressed in terms of unknown parameters of the reference plane, which is usually taken at the middle plane of the plate. In this context, the first-order shear deformation theory (FSDT) (Yang et al., 1996) may be

\footnotetext{
* To whom correspondence should be addressed
} 
considered as the simplest option. In this theory, the transverse shear strain is assumed to have uniform variation over the entire plate thickness (i.e., the transverse shear stress is constant). It is also known as Reissner-Mindlin's plate theory.

Goyal and Kapania (2007) developed a five node beam FE model of twenty four degrees of freedom, based on FSDT for static as well as dynamic analysis. However, these theories (FSDT) require a shear correction factor to compensate for the actual parabolic variation of the shear stress but there are some improvements, which allow the warping of plate sections to have a higher-order variation of transverse shear stresses/strains along the thickness. The performance of the first-order shear deformation theory is strongly dependent on shear correction factors (Vlachoutsis, 1992).

For a better representation of the transverse shear deformations, higher order shear deformation theories (HSDT) are proposed by Lo et al. (1977); Reddy (1984); Kant (1982); Manjunatha et al. (1992) and a few others, with the aim to avoid the use of shear correction factors, to include actual cross sectional warping and to get the realistic variation of the transverse shear strains and stresses through the plate thickness. Kant (1982) derived the complete set of governing equations for the analysis of both thick and thin elastic plates with the help of a refined higher order theory. This theory was based on a higher order displacement model and the three-dimensional Hooke's laws for the plate material, it gives rise to a more realistic quadratic variation of the transverse shearing strains and linear variation of the transverse normal strain through the plate thickness and Manjunatha and Kant (1992) proposed a $C^{0}$ finite element model based on the same higher order theory (Kant, 1982) for reliable predictions of interlaminar stresses in layered composite and sandwich laminates. Later, Kant and Swaminathan (2002) reported analytical solutions for the static analysis of laminated composite and sandwich plates based on the higher order refined theory (Kant, 1982) and thus eliminated the need for shear correction factors. Using Reddy's displacement field for the third order shear deformation theory, a set of dynamic equations was derived for modelling the behaviour of a laminated plate by Aagaah et al. (2003). Pervez et al. (2005) presented a two dimensional serendipity model based on HSDT for the static analysis of a laminated composite plate. Wu et al. (2005) presented $C^{l}$ four node quadrilateral element and $C^{l}$ three node triangular element developed on the basis of the global local higher order shear deformation theory for the static analysis of an angle-ply laminated plate. Kulkarni and Kapuria (2007) proposed a new discrete Kirchhoff quadrilateral element based on Reddy's HSDT. Aydogdu (2009) presented HSDT for the static, vibration and buckling analysis of laminated composite plates, where the shear deformation function was chosen according to 3-D results by using the inverse method. A nine-node rectangular element with nine degrees of freedom at each node based on HSDT was developed by $\mathrm{Tu}$ et al. (2010) for the bending and vibration analysis of laminated and sandwich composite plates. Ferreira et al. (2011) presented the radial basis function collocation method for the static and vibration analysis of thick plates using FSDT and HSDT of Kant. For the analysis of thin and thick composite plates, Roque et al. (2011) used the higher order shear deformation theory and a radial basis function. Recently, Zhen et al. (2012) described the short coming of zigzag theories, i.e., the requirement of $C^{l}$ continuity condition and presented an eight node $C^{0} \mathrm{FE}$ model by taking out the first derivatives of transverse displacements from the in-plane displacement fields for the static analysis of laminated sandwich plates. Due to different values of shear rigidity at the adjacent layers, HSDT shows discontinuity in the shear stress distribution at the layer interfaces, and a continuous variation of the transverse shear strain across the thickness. But the actual behavior of a composite laminate is opposite, i.e., the transverse shear stress must be continuous at the layer interface and the corresponding strain may be discontinuous (Sheikh and Chakrabarti, 2003).

In order to overcome the above disparity, Srinivas (1973), Toledano and Murakami (1987), Robbins et al. (1993), Li et al. (1995), and some other investigators proposed layer-wise plate theories. The layerwise theories may be classified as a discrete layer plate theory and refined plate theory. In the discrete layer plate theory unknown displacement components are taken at all the layer interfaces. Discrete layer theories proposed by Toledeno and Murakami (1987), Reddy (1987), Li and Liu (1995), Robbins and Reddy (1996) and many others assume a unique displacement field in each layer and displacement continuity across the layers. Ramesh et al. (2009) presented a 45-node triangular element with 7 degrees of freedom at each node, based on the HSDT and layer-wise plate theory of Reddy for the static analysis of the laminated composite 
plate. The performance of this plate theory is good but it required huge computational involvement in analyzing a multi-layered plate since the number of unknowns increases directly with the increase in the number of layers.

A major development in this direction is due to Di Sciuva (1984), Liu and Li (1996), Murakami (1986) and few others. They proposed a zigzag plate theory (also called the refined plate theory) where the layer-wise theory is initially used to represent the in-plane displacements having piecewise linear variation across the plate thickness. The unknowns at the different interfaces are subsequently expressed in terms of those at the reference plane through satisfaction of transverse shear stress continuity at the layer interfaces and this makes the number of unknowns to be independent of the number of layers. In some improved version of these theories, the condition of zero transverse shear stresses at the plate/beam top and bottom was also satisfied. The theories developed by Murakami (1986), Di Sciuva (1987), Lee et al. (1990), Cho and Parmerter (1993), Cho and Averill (1997), and many others fall under this category.

A further improvement in this direction is due to Cho and Parmerter (1992), Di Sciuva (1992), Bhaskar and Varadan (1989), and some other investigators who considered the variation of in-plane displacements to be a superposition of a piecewise linearly varying field on an overall globally higher order variation. Carrera (2004) and Demasi (2005) considered higher order terms in the displacement field, using Mukarmi's (Mukarmi, 1986) zigzag function and the assumptions for interlaminar continuity of transverse stresses. However applying the static condensation technique makes it possible to eliminate the unknowns related to the interlaminar continuity of transverse stresses and thus, to derive efficient plate theories (Demasi, 2009a; 2009b).

A triangular element was presented by Chakrabarti and Sheikh (2004) based on the zigzag theory, which shows excellent performance though the element does not satisfy the normal slope continuity requirement. Akhras and Li (2007) developed a spline finite strip method based on Cho's higher order zigzag theory for the static analysis of the plate. Kapuria and Kulkarni (2007) presented a four node quadrilateral element based on the third order zigzag theory for the analysis of laminates. The need of $C^{l}$ continuity requirement is circumvented by using a discrete Kirchoff constraint approach, where the derivaties of transverse displacement are replaced by rotational variables. Fares and Elmarghany (2008) developed a first order zigzag theory of composite plates using Ressiner's mixed variational formula. Recently, Ferreira et al. (2011) and Rodrigues et al. (2011) presented radial basis functions- finite differences collocation and unified formulation for the analysis of laminated plates based on Murkami's zigzag theory. These theories (zigzag) provide a very accurate approximation of the structural behavior even for a lower span to thickness ratio. However, the zigzag theory has a problem in its finite element implementation as it requires $C^{l}$ continuity of the transverse displacement at the nodes. Zhen and Wanji (2010) proposed $C^{0}$ type higher-order theory for bending analysis of laminated composite and sandwich plates. However, in this article, the analytical formulations and solutions are only presented for thermo-mechanical bending analysis of laminated composite and sandwich plates. Zhen et al. (2010) also proposed $C^{0}$ type finite element based higher-order theory for accurately predicting natural frequencies of sandwich plates with soft core. These theories are usually referred as refined higher order shear deformation theory (RHSDT). However, there are very few $C^{0}$ elements reported in the literature which can model the RHSDT.

To combine the benefits of the discrete layer-wise and higher order zigzag theories, Icardi (2001a; 2003b), Yip and Averill (1996) and many other authors developed theories which are known as sublaminated models. Cho and Averill (2000) presented an improved sub-laminate model with the first order zigzag approximation of displacement within each sub-laminate, which contains an eight node $C^{0}$ finite element (FE) having five displacement degrees of freedom in each node for each sub-laminate. Averill (1994) developed a $C^{0}$ finite element based on the first order zigzag theory and overcame the $C^{l}$ continuity requirement by incorporating the concepts of independent interpolations and penalty functions. Hermitian functions were used by Di Sciuva $(1995 \mathrm{a} ; 1993 \mathrm{~b})$ to approximate the transverse displacement in his formulations. Carrera (1996) used two different fields along the laminate thickness direction for displacement and transverse shear stress respectively for his formulation. Averill and Yip (1996) developed a $C^{0}$ finite element based on the cubic zigzag theory, using interdependent interpolations for transverse displacement and rotations and penalty function concepts. Aitharaju and Averill (1999) developed a new $C^{0}$ 
FE based on a quadratic zigzag layer-wise theory. For eliminating shear locking phenomenon, the shear strain field is also made field consistent. The transverse normal stress was assumed to be constant through the thickness of the laminate. The new finite element FE was applied to model the beam as a combination of different sub-laminates.

A $C^{0}$ plate model based on enhanced first order theory (EFSDT) was presented by Kim and Cho (2005a; 2006b), where it was shown that the displacements, in-plain strains and stresses can be approximated to those of the three dimensional theory or higher order theory, in the least square sense. Recently, Kim and Cho (2007) developed a $C^{0}$ model using the EFSDT based on the mixed variational theorem, which also satisfies the lateral conditions at the top and bottom surfaces of the plate. The mixed FE approach was presented by Rao et al. (2001), Ramtekekar et al. (2002a; 2003b), Bambole and Desai (2007) and many others, where the stress components were assumed as degrees of freedom at interface nodes along with displacement degrees of freedom for the accurate analysis of the stresses.

Laminated soft core sandwich structures are extensively used mainly in weight minimization applications. The transverse deformation is very significant in the sandwich structure as there is an abrupt change in the values of transverse shear rigidity and thickness of the face sheet and the core. As such more attention must be given for the accurate modeling of the variation of transverse deflection across the depth of a sandwich structure having a soft core. Frostig (2003) presented the classical and the higher order computational models of unidirectional sandwich panels with incompressible and compressible cores to demonstrate the differences in overall response of the panels as well as in the vicinity of the localized loads and supports. Givil et al. (2007) presented the dynamic model based on the higher order sandwich panel theory to study the behavior of the soft core sandwich panel under dynamic loading.

So it is required to introduce unknown transverse displacement fields across the depth in addition to that in the reference plane to represent the variation of transverse deflection in a laminated sandwich structure. This can be done by using sub-laminate plate theories but the number of unknowns will increase rapidly with the increase in the number of sub-laminates. On the other hand, an introduction of additional unknowns in the transverse displacement fields invites additional $C^{l}$ continuity requirements in its finite element implementation by using the zigzag theory as mentioned earlier. Moreover, the application of a $C^{l}$ continuous finite element is not encouraged in a practical analysis. Recently, Pandit et al. (2008a; 2008b) proposed a higher order zigzag theory for the analysis of sandwich plates with a soft compressible core. To circumvent the above problem of $C^{l}$ continuity they used separate shape functions to define the derivatives of transverse displacements in order to develop a $C^{0}$ finite element model for the implementation of the proposed higher order zigzag theory. However, it imposed some constrains, which are enforced variationally through penalty approach. The selection of a suitable value for the penalty stiffness multiplier is quite arbitrary and is a well known problem in the finite element method. Recently, Chakrabarti et al. (2011) proposed a new FE model based on the higher order zigzag theory for the static analysis of a laminated sandwich beam with a soft core. However, the FE model proposed in this paper is based on the one dimensional static analysis of a sandwich beam and as such there a need of further improvement in the FE model formulation which can be used for laminated sandwich plates with a soft core.

An efficient $C^{0}$ finite element model based on the higher order zigzag theory is proposed in this paper for the analysis of a sandwich plate with a soft compressible core. In this model, the in-plane displacement fields are assumed as a combination of a linear zigzag function with different slopes at each layer and a global cubically varying function over the entire thickness. The transverse displacement is considered to be quadratic within the core and constant in the face sheets. The proposed model satisfies the transverse shear stress continuity conditions at the layer interfaces and the zero transverse shear stress condition at the top and bottom of the plate. The isoparametric quadratic plate element has nine nodes with eleven field variables (i.e., in-plane displacements and transverse displacement at the reference mid surface, at the top and at the bottom of the plate along with rotational degrees of freedom at the reference mid surface and top and bottom of the plate) at each node. The displacement fields are chosen in an efficient manner that there is no need to impose any penalty stiffness in the formulation. The element may also be matched quite conveniently with other $C^{0}$ elements. 
The present plate model is used to solve many problems having different loadings, geometry boundary conditions and others. The present FE model is capable of analyzing laminated sandwich structures having a soft compressible core very accurately.

\section{Mathematical formulations}

\subsection{FE Model for displacements and in-plane stresses evaluation}

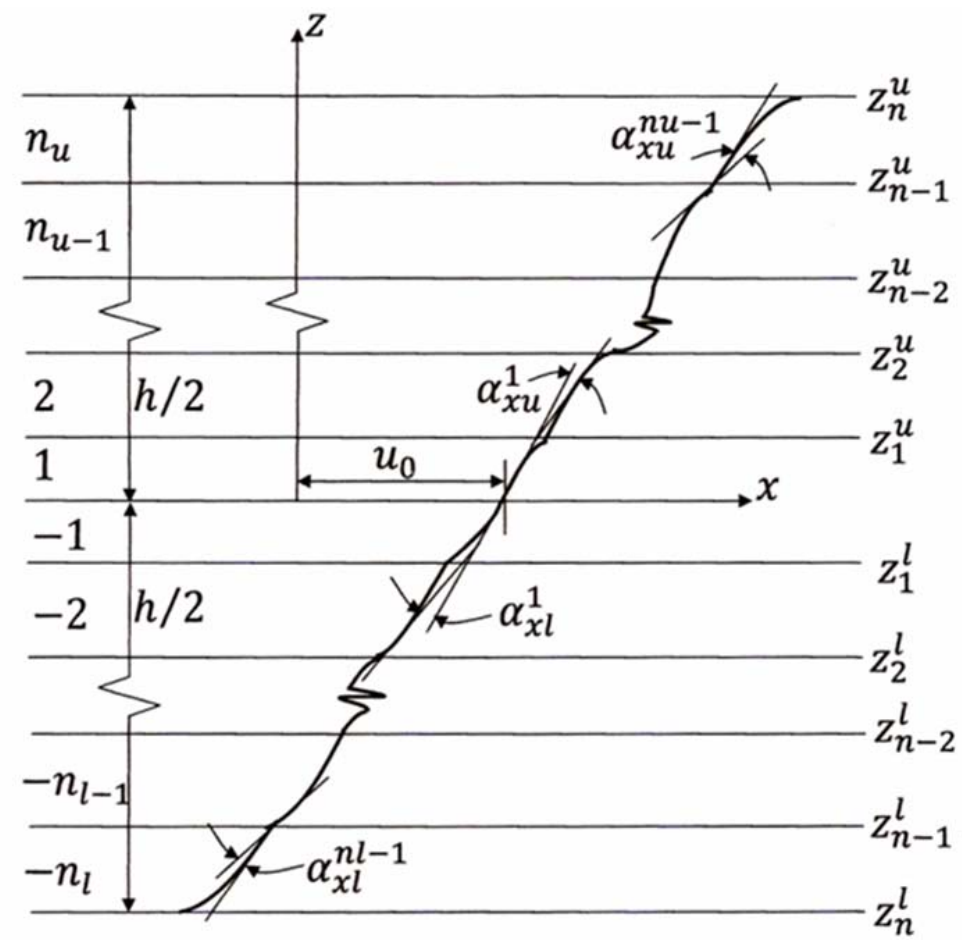

Fig.1. General lamination lay-up and displacement configuration.

The in-plane displacement field (Fig.1) is chosen as follows

$$
\begin{aligned}
& U=u_{0}+z \theta_{x}+\sum_{i=1}^{n_{u}-1}\left(z-z_{i}^{u}\right) H\left(z-z_{i}^{u}\right) \alpha_{x u}^{i}+\sum_{j=1}^{n_{l}-1}\left(z-z_{j}^{l}\right) H\left(-z+z_{j}^{l}\right) \alpha_{x l}^{j}+\beta_{x} z^{2}+\eta_{x} z^{3}, \\
& V=v_{0}+z \theta_{y}+\sum_{i=1}^{n_{u}-1}\left(z-z_{i}^{u}\right) H\left(z-z_{i}^{u}\right) \alpha_{y u}^{i}+\sum_{j=1}^{n_{l}-1}\left(z-z_{j}^{l}\right) H\left(-z+z_{j}^{l}\right) \alpha_{y l}^{j}+\beta_{y} z^{2}+\eta_{y} z^{3}
\end{aligned}
$$

where, $u_{0}$ and $v_{0}$ denote the in-plane displacements of any point on the middle surface (i.e., $u_{0}$ along the $x$ axis and $v_{0}$ along the $y$-axis) of any point on the mid surface, $\theta_{x}$ and $\theta_{y}$ are the rotations of the normal to the middle plane about the $x$-axis and $y$-axis respectively, $n_{u}$ and $n_{l}$ are the number of upper and lower layers, respectively, $\beta_{x}, \beta_{y}, \eta_{x}$ and $\eta_{y}$ are the higher order unknown, $\alpha_{x u}^{i}, \alpha_{y u}^{i}, \alpha_{x l}^{j}$ and $\alpha_{y l}^{j}$ are the slopes of $i$-th $/ j$-th layer corresponding to the upper and lower layers, respectively and $H\left(z-z_{i}^{u}\right)$ and $H\left(-z+z_{j}^{l}\right)$ are the unit step functions. 


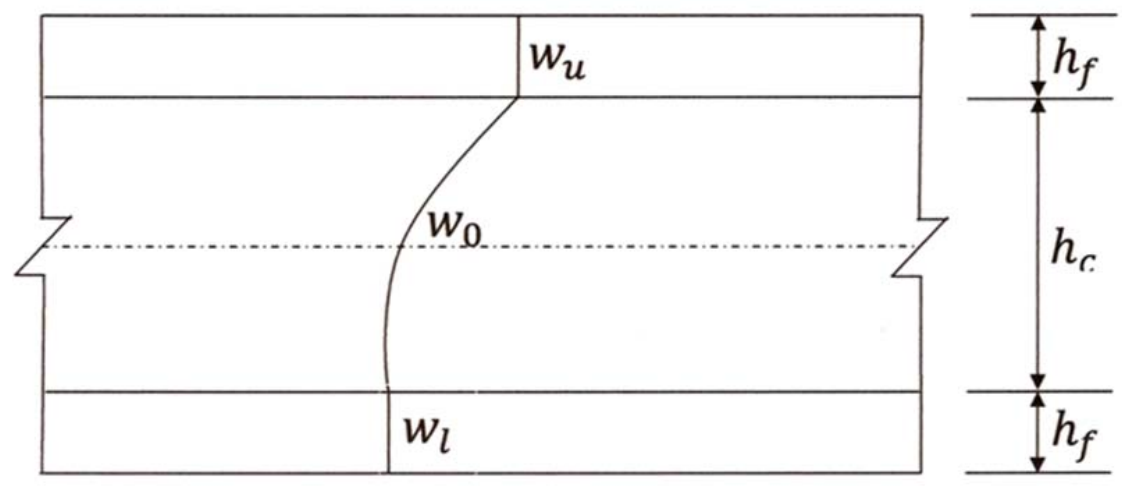

Fig.2. Transverse displacement $(w)$ variation through the thickness of the sandwich plate.

The transverse displacement is assumed to vary quadratically through the core thickness and constant over the face sheets (as shown in Fig.2) and it may be expressed as

$$
\begin{aligned}
& W=l_{l} w_{u}+l_{2} w_{0}+l_{3} w_{l} \quad \text { for the core region, } \\
& =w_{u} \quad \text { for upper face layers, } \\
& =w_{l} \quad \text { for lower face layers }
\end{aligned}
$$

where $w_{u}, w_{0}$ and $w_{l}$ are the values of the transverse displacement at the top layer, middle layer and bottom layer of the core, respectively, and $l_{1}, l_{2}$ and $l_{3}$ are Lagrangian interpolation functions in the thickness coordinate as defined below.

$$
l_{1}=\frac{z\left(z+h_{l}\right)}{h_{u}\left(h_{u}+h_{u}\right)}, \quad l_{2}=\frac{\left(h_{l}+z\right)\left(h_{u}-z\right)}{h_{u} h_{l}}, \quad l_{3}=\frac{z\left(h_{u}-z\right)}{-h_{l}\left(h_{u}+h_{l}\right)} .
$$

The stress-strain relationship considering the plane strain condition of an orthotropic layer/ lamina (say $k$-th layer) having any fiber orientation with respect to structural axes system $(x-z)$ may be expressed as

$$
\left\{\begin{array}{c}
\sigma_{x x} \\
\sigma_{y y} \\
\sigma_{z z} \\
\tau_{x y} \\
\tau_{x z} \\
\tau_{y z}
\end{array}\right\}=\left[\begin{array}{cccccc}
\bar{Q}_{11} & \bar{Q}_{12} & \bar{Q}_{13} & \bar{Q}_{14} & 0 & 0 \\
\bar{Q}_{21} & \bar{Q}_{22} & \bar{Q}_{23} & \bar{Q}_{24} & 0 & 0 \\
\bar{Q}_{31} & \bar{Q}_{32} & \bar{Q}_{33} & \bar{Q}_{34} & 0 & 0 \\
\bar{Q}_{4} & \bar{Q}_{42} & \bar{Q}_{43} & \bar{Q}_{44} & 0 & 0 \\
0 & 0 & 0 & 0 & 0 & 0 \\
0 & 0 & 0 & 0 & 0 & 0
\end{array}\right]_{K}\left\{\begin{array}{c}
\varepsilon_{x x} \\
\varepsilon_{y y} \\
\varepsilon_{z z} \\
\gamma_{x y} \\
\gamma_{x z} \\
\gamma_{y z}
\end{array}\right\} \text { or }\{\bar{\sigma}\}=\left[\bar{Q}_{K}\right]\{\bar{\varepsilon}\}
$$

where $\{\bar{\sigma}\},\{\bar{\varepsilon}\}$ and $\left[\bar{Q}_{K}\right]$ are the stress vector, the strain vector and the transformed rigidity matrix of $k$-th lamina, respectively.

Utilizing the conditions of zero transverse shear stress at the top and bottom surfaces of the plate and imposing the conditions of the transverse shear stress continuity at the interfaces between the layers along with the conditions, $\theta_{x}=\theta_{x}^{u}$ and $\theta_{y}=\theta_{y}^{u}$ at the top and $\theta_{x}=\theta_{x}^{l}$ and $\theta_{y}=\theta_{y}^{l}$ at the bottom of the plate, $\beta_{x}$, 
$\eta_{x}, \beta_{y}, \eta_{y}, \alpha_{x u}^{i}, \alpha_{x l}^{i}, \alpha_{y u}^{i}, \alpha_{y l}^{i},\left(\partial w_{u} / \partial x\right),\left(\partial w_{l} / \partial x\right),\left(\partial w_{u} / \partial y\right)$ and $\left(\partial w_{l} / \partial y\right)$ may be expressed in terms of the displacements $u_{0}, v_{0}, \theta_{x}, \theta_{y}, \theta_{x}^{u}, \theta_{y}^{u}, \theta_{x}^{l}$ and $\theta_{y}^{l}$ as

$$
\{B\}=[A]\{\alpha\}
$$

where

$$
\begin{aligned}
& \{B\}=\left\{\beta_{x} \eta_{x} \beta_{y} \eta_{y} \alpha_{x u}^{1} \alpha_{x u}^{2} \ldots \alpha_{x u}^{n u-1} \alpha_{x l}^{1} \alpha_{x l}^{2} \ldots \alpha_{x l}^{n l-1} \alpha_{y u}^{1} \alpha_{y u}^{2} \ldots \alpha_{y u}^{n u-1} \alpha_{y l}^{1} \alpha_{y l}^{2} \ldots \alpha_{y l}^{n l-1}\right. \\
& \left.\left(\partial w_{u} / \partial x\right)\left(\partial w_{u} / \partial y\right)\left(\partial w_{l} / \partial x\right)\left(\partial w_{l} / \partial y\right)\right\}^{T}, \\
& \{\alpha\}=\left\{u_{0} v_{0} \theta_{x} \theta_{y} \theta_{x}^{u} \theta_{y}^{u} \theta_{x}^{l} \theta_{y}^{l}\right\}^{T},
\end{aligned}
$$

and the elements of $[A]$ are dependent on material properties. It is to be noted that last four entries of the vector $\{B\}$ help to define the derivatives of transverse displacement at the top and bottom faces of the plate in terms of the displacements $u_{0}, v_{0}, \theta_{x}, \theta_{y}, \theta_{x}^{u}, \theta_{y}^{u}, \theta_{x}^{l}$ and $\theta_{y}^{l}$ to overcome the problem of $C_{l}$ continuity as mentioned before.

Using the above equations, the in-plane displacement fields as given in Eqs (2.1)-(2.2) may be expressed as

$$
\begin{aligned}
& U=b_{1} u_{0}+b_{2} v_{0}+b_{3} \theta_{x}+b_{4} \theta_{y}+b_{5} \theta_{x}^{u}+b_{6} \theta_{y}^{u}+b_{7} \theta_{x}^{l}+b_{8} \theta_{y}^{l}, \\
& V=c_{1} u_{0}+c_{2} v_{0}+c_{3} \theta_{x}+c_{4} \theta_{y}+c_{5} \theta_{x}^{u}+c_{6} \theta_{y}^{u}+c_{7} \theta_{x}^{l}+c_{8} \theta_{y}^{l}
\end{aligned}
$$

where the coefficients $b_{i}$ 's and $\mathrm{c}_{i}$ 's are the function of thickness coordinates, unit step functions and material properties as defined in Appendix A.

The generalized displacement vector $\{\delta\}$ for the present plate model can now be written with the help of Eqs (2.3), (2.6) and (2.7) as

$$
\{\delta\}=\left\{u_{0} v_{0} w_{0} \theta_{x} \theta_{y} \theta_{x}^{u} \theta_{y}^{u} w_{u} \theta_{x}^{l} \theta_{y}^{l} w_{l}\right\}^{T} .
$$

Using the linear strain-displacement relation and Eqs (2.1)-(2.5), the strain field may be expressed in terms of unknowns (for the structural deformation) as

$$
\left\{\frac{-}{\varepsilon}\right\}=\left[\frac{\partial U}{\partial x} \frac{\partial V}{\partial y} \frac{\partial W}{\partial z} \frac{\partial U}{\partial x}+\frac{\partial V}{\partial y} \frac{\partial U}{\partial z}+\frac{\partial W}{\partial x} \frac{\partial V}{\partial z}+\frac{\partial W}{\partial x}\right] \quad \text { or } \quad\{\bar{\varepsilon}\}=\left[H_{0}\right]\{\varepsilon\}
$$

where

$$
\begin{aligned}
& \{\varepsilon\}=\left[u_{0} v_{0} w_{0} \theta_{x} \theta_{y} u_{u} v_{u} w_{u} u_{l} v_{l} w_{l}\left(\partial u_{0} / \partial x\right)\left(\partial u_{0} / \partial y\right)\left(\partial v_{0} / \partial x\right)\left(\partial v_{0} / \partial y\right)\left(\partial w_{0} / \partial x\right)\left(\partial w_{0} / \partial y\right)\left(\partial \theta_{x} / \partial x\right)\left(\partial \theta_{x} / \partial y\right)\right. \\
& \left(\partial \theta_{y} / \partial x\right)\left(\partial \theta_{y} / \partial y\right)\left(\partial u_{u} / \partial x\right)\left(\partial u_{u} / \partial y\right)\left(\partial v_{u} / \partial x\right)\left(\partial v_{u} / \partial y\right)\left(\partial w_{u} / \partial x\right)\left(\partial w_{u} / \partial y\right) \\
& \left.\left(\partial u_{l} / \partial x\right)\left(\partial u_{l} / \partial y\right)\left(\partial v_{l} / \partial x\right)\left(\partial v_{l} / \partial y\right)\left(\partial w_{l} / \partial x\right)\left(\partial w_{l} / \partial y\right)\right]
\end{aligned}
$$

and the elements of $\left[H_{0}\right]$ are functions of $z$ and unit step functions, as given in Appendix B.

With the quantities found in the above equations, the total potential energy of the system under the action of a transverse load may be expressed as

$$
\Pi_{e}=U_{s}-W_{e x t}
$$


where $U_{s}$ is the strain energy and $W_{\text {ext }}$ is the energy due to the external transverse static load.

Using Eqs (2.3) and (2.6), the strain energy $\left(U_{s}\right)$ is given by

$$
U_{s}=\frac{1}{2} \sum_{k=1}^{n} \iiint\{\bar{\varepsilon}\}^{T}\left[\bar{Q}_{k}\right]\{\bar{\varepsilon}\} d x d y d z=\frac{1}{2} \iint\{\varepsilon\}^{T}[D]\{\varepsilon\} d x d y
$$

where $\quad[D]=\sum_{k=1}^{n} \int\left[H_{0}\right]^{T}\left[\bar{Q}_{k}\right]\left[H_{0}\right] d z$

and the energy due to the externally applied distributed transverse static load of intensity $q(x, y)$ can be calculated as

$$
W_{\text {ext. }}=\iint w q d x d y
$$

In the present problem, a nine-node quadratic element with eleven field variables $\left(u_{0}, v_{0}, w_{0}, \theta_{x}, \theta_{y}, u_{u}\right.$, $v_{u}, w_{u}, u_{l}, v_{l}$ and $\left.w_{l}\right)$ per node is employed. Using the finite element method the generalized displacement vector $\{\delta\}$ at any point may be expressed as

$$
\{\delta\}=\sum_{i=1}^{n} N_{i} \delta_{i}
$$

where, $\{\delta\}=\left\{u_{0} v_{0} w_{0} \theta_{x} \theta_{y} \theta_{x}^{u} \theta_{y}^{u} w_{u} \theta_{x}^{l} \theta_{y}^{l} w_{l}\right\}^{T}$ as defined earlier, $\delta_{i}$ is the displacement vector corresponding to node $i, N_{i}$ is the shape function associated with the node $i$ and $N$ is the number of nodes per element, which is nine in the present study.

With the help of Eq.(2.14), the strain vector $\{\varepsilon\}$ that appeared in Eq.(2.9) may be expressed in terms of unknowns (for the structural deformation) as

$$
\{\varepsilon\}=[B]\{\delta\}
$$

where $[B]$ is the strain-displacement matrix in the Cartesian coordinate system.

The elemental potential energy as given in Eq.(2.10) may be rewritten with the help of Eqs (11)-(15) as

$$
\begin{aligned}
& \Pi_{\mathrm{e}}=\frac{1}{2} \iint\{\delta\}^{T}[B]^{T}[D][B]\{\delta\} d x d y-\frac{1}{2} \iint\{\delta\}^{T}[B]^{T}\left[N^{w}\right]^{T} q d x d y \\
& =\frac{1}{2}\{\delta\}^{T}\left[K_{e}\right]\{\delta\}-\frac{1}{2}\{\delta\}^{T}\left\{P_{e}\right\}
\end{aligned}
$$

where

$$
\begin{aligned}
& {\left[K_{e}\right]=\int[B]^{T}[D][B] d x,} \\
& \left\{P_{e}\right\}=\iint\left[N^{w}\right]^{T} q d x d y
\end{aligned}
$$

where, $\left[N^{w}\right]$ is the shape function like matrix with non-zero terms associated only with the corresponding transverse nodal displacements.

The equilibrium equation can be obtained by minimizing $\Pi_{e}$ as given in Eq.(2.16) with respect to $\{\delta\}$ as 


$$
\left[K_{e}\right]\{\delta\}=\left\{P_{e}\right\}
$$

where $\left[K_{e}\right]$ is the element stiffness matrix and $\left\{P_{e}\right\}$ is the nodal load vector. The integration involved in the above expressions is carried out numerically by following the consistent integration schemes in order to avoid the shear locking problems.

The global stiffness matrix and global load vector for the whole plate is then formed by taking the contribution of all the plate elements. Finally, the global linear simultaneous equations are formed and solved for the problem of the sandwich plate after incorporation of appropriate boundary conditions. The in-plane stresses are calculated with the help of a constitutive relationship by using the condition of stress continuity as in Eq.(2.4). Since it is very difficult to accurately evaluate the transverse stresses using 2D FE models available in the literature therefore the least square error (LSE) method proposed by Khandelwal et al. (2012), is used to calculate these transverse stresses accurately at the post processing stage. The details of the LSE method are not presented here, it can be obtained from Khandelwal et al. (2012).

A numerical code is developed to implement the above mentioned operations involved in the proposed FE model to calculate deflections and stresses in the sandwich plate. The skyline technique has been used to store the global stiffness matrix in a single array and Gaussian decomposition scheme is adopted for the solution.

The following different boundary conditions are used:

1. Boundary line parallel to the $x$ axis

- Simply supported condition: The degrees of freedoms $u_{0}, v_{0}, w_{0}, \theta_{x}, \theta_{x}^{u}, \theta_{x}^{l}, w_{u}, w_{l}$ are restrained while $\theta_{y}, \theta_{y}^{u}$ and $\theta_{y}^{l}$ are unrestrained.

- Clamped condition: All the nodal degrees of freedom at the boundary are fully restrained.

- Free boundary condition: All the nodal degrees of freedom at the boundary are unrestrained.

2. Boundary line parallel to the $y$ axis

- Simply supported condition: The degrees of freedoms $u_{0}, v_{0}, w_{0}, \theta_{y}, \theta_{y}^{u}, \theta_{y}^{l}, w_{u}, w_{l}$ are restrained while $\theta_{x}, \theta_{x}^{u}$ and $\theta_{x}^{l}$ are unrestrained.

- Clamped condition: All the nodal degrees of freedom at the boundary are fully restrained.

- Free boundary condition: All the nodal degrees of freedom at the boundary are unrestrained.

\section{Numerical results and discussions}

In order to demonstrate the accuracy and applicability of the proposed $C^{0}$ plate FE model based on the refined higher order shear deformation theory (RHSDT) and the least square error method (LSE) a number of numerical problems on composites and laminated sandwich plates are solved under static loading. The general geometric details of the plate problem considered for different problems are shown in Fig.3. The results obtained are presented in the form of different tables and figures. Initially, a composite plate problem is solved by using the proposed model to study the displacement convergence and also to compare the present results with some already published results. Finally, the proposed model is applied to solve many problems to generate results in the form of deflections and stresses. An accurate calculation of the deflection and transverse shear stresses in different cases is the main feature of all these studies.

A multiplication factor $m=100 E_{2 f} h^{3} / q a^{4}$ is used to make non-dimensional the transverse displacement (w), $m=h^{2} / q a^{2}$ is used to make non-dimensional the in-plane stresses $\left(\sigma_{x x}, \sigma_{y y}, \sigma_{x y}\right)$ and $m=h / q a$ is used to make non-dimensional the transverse shear stresses $\left(\sigma_{x z}, \sigma_{y z}\right)$, where $E_{2 f}$ is the elastic constant of the ply material in the $y$ direction, $h$ is the total thickness of the plate, $a$ is the least dimension of the plate plan form and $q$ is the magnitude of the applied static load on the plate. 


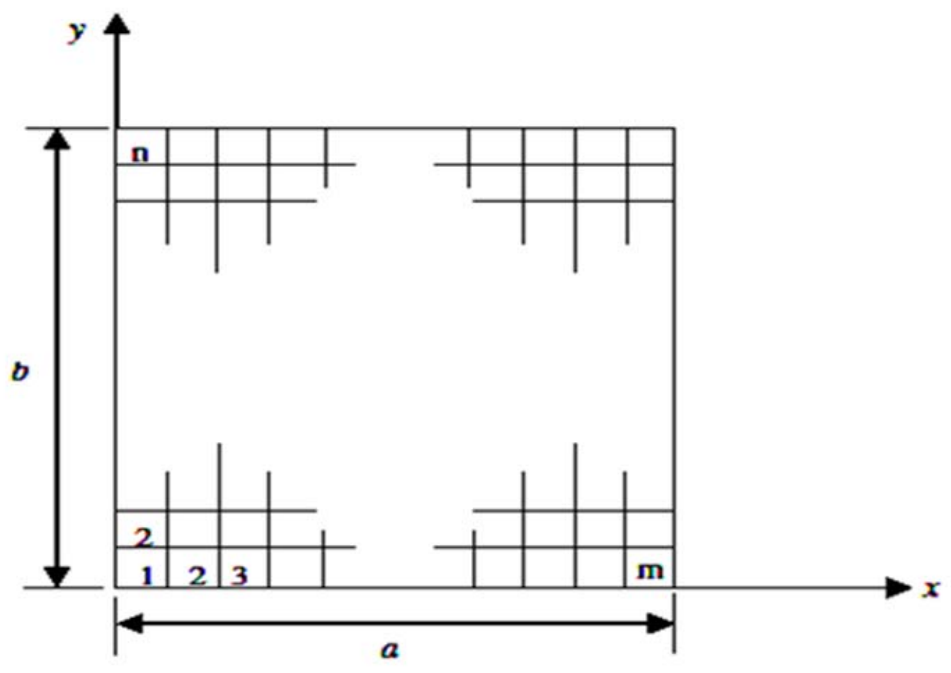

Fig.3. Rectangular plate having a mesh of $m \times n$.

\subsection{Rectangular Cross-ply (0/90/0) laminate subjected to distributed load of sinusoidal variation}

The plate as shown in Fig.3 is simply supported at its four edges and subjected to static sinusoidal load distribution $q(x, y)=q_{0} \sin (\pi x / a) \sin (\pi y / b)$. The study is made for two different aspect ratios $(b / a=1.0$ and $b / a=3.0)$. For the aspect ratio $b / a=1.0$, the thickness ratio $(h / a)$ is taken as $0.5,0.1$ and 0.01 and for the aspect ratio $b / a=3.0$, the thickness ratio $(h / a)$ is taken as $0.5,0.1,0.05$ and 0.01 , respectively. In all the cases the full plate is analyzed with different mesh divisions (Fig.3). The non-dimensional displacements (transverse) and stresses (in-plane normal and transverse shear) obtained using constitutive relations at the important locations are presented in Tab.2 and Tab.3 mainly to study the rate of convergence and validation of the displacements and stresses. It may be observed in Tab.2 and Tab.3 that the displacements are converged at mesh division $(8 \times 8)$. However, more mesh divisions are required for the convergence of the stresses as expected. As such a mesh division of $(12 \times 12)$ is taken for all subsequent analyses to get sufficiently accurate results corresponding to displacement as well as stresses.

Table 1. Material properties used for the core and face sheets.

\begin{tabular}{|cccccccccc|}
\hline Location & \multicolumn{10}{c|}{ Elastic properties } \\
& $E_{1}$ & $E_{2}$ & $E_{3}$ & $G_{12}$ & $G_{13}$ & $G_{23}$ & $v_{12}$ & $v_{13}$ & $v_{32}$ \\
Face & 25.0 & 1.0 & 1.0 & 0.5 & 0.5 & 0.2 & 0.25 & 0.25 & 0.25 \\
Core & 0.04 & 0.04 & 0.5 & 0.016 & 0.06 & 0.06 & 0.25 & 0.02 & 0.25 \\
\hline
\end{tabular}

For the comparison of the present results a computer code is also developed to generate results based on the 3-D elasticity solution of Pagano (1970) corresponding to the plane strain condition. The present FE results are also compared with the results obtained by Ramesh et al. (2009) using a 45-node triangular element with seven field unknowns at each node based on LT and TSDT. The total number of unknowns per element is 99 in the present element as compared to 315 in Ramesh et al. (2009) case. The results reported by Wu et al. (2012), Kulkarni et al. (2007), Aydogdu (2009), Liou and Sun (1987) and Sheikh and Chakrabarti (2003) based on HSDT and the analytical results reported by Reddy (19984) and Kant and Swaminathan (2002) are also used to show the accuracy of the present model. From Tab.2, it may be observed that the performance of the present FE model is quite good for predicting the deflections with sufficient accuracy as compared to other models especially at a higher thickness ratio $(h / a)$ with a smaller number of element degrees of freedom.

Now, the through-the-thickness variations of normalized in-plane normal stresses $\left(\sigma_{x x}, \sigma_{y y}\right)$ are obtained at the plate center $(a / 2, b / 2)$ in the present analysis (mesh size: $12 \times 12, b / a=1, h / a=0.1$ and 
$h / a=0.25$ ), and are plotted with the 3D elasticity solution Pagano (1970) in Figs 4-5. The figures show that the present results are in excellent agreement with the elasticity solution.
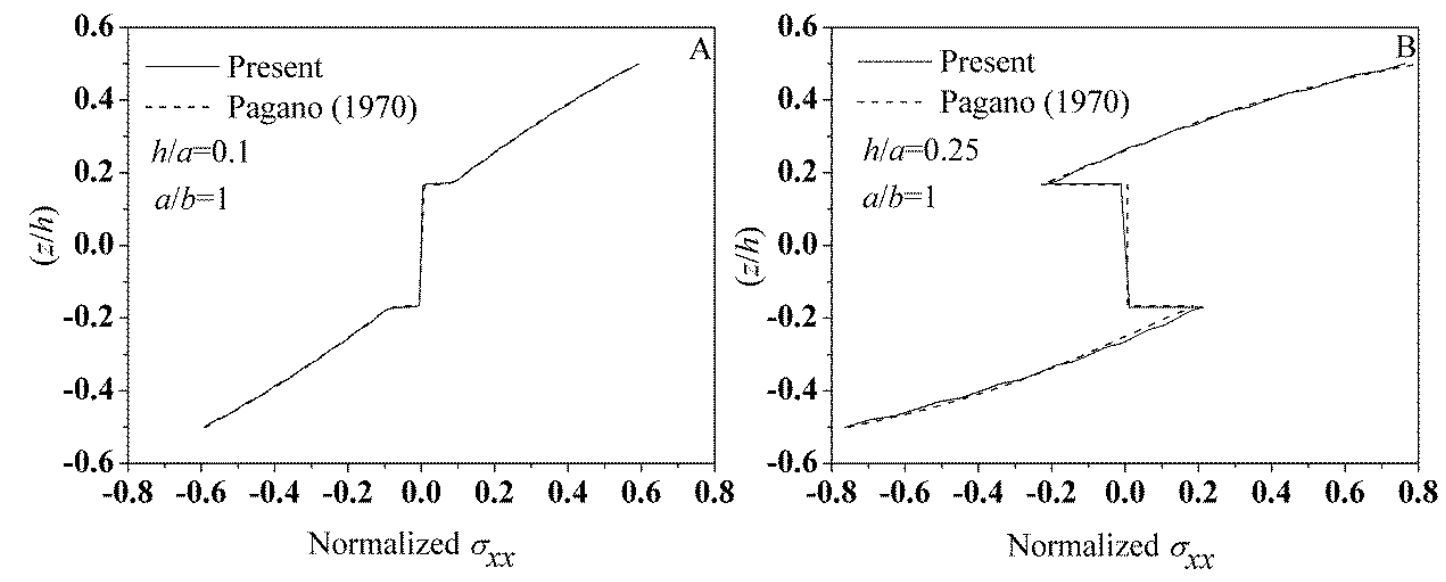

Fig.4. Through thickness variation of normalized in-plane stress $\sigma_{x x}$ (at $x=a / 2, y=b / 2$ ) for rectangular crossply $(0 / 90 / 0)$ plate under simple support condition and subjected to sinusoidal loading.
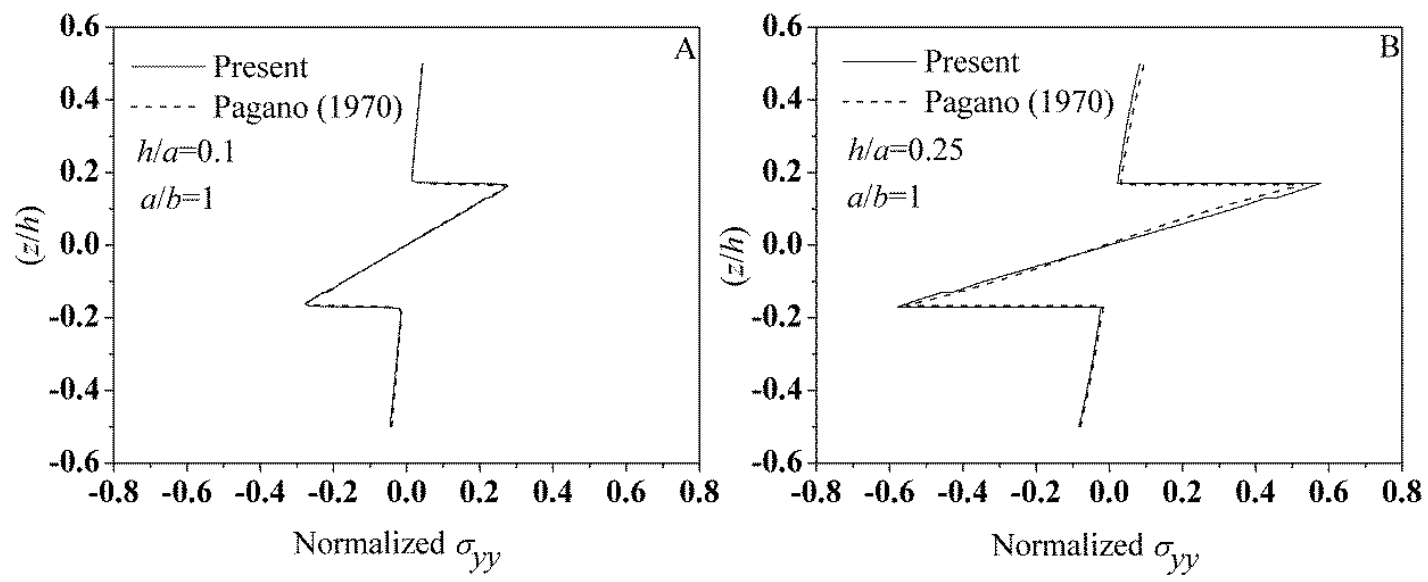

Fig.5. Through thickness variation of normalized in-plane stress $\sigma_{y y}($ at $x=a / 2, y=b / 2)$ for rectangular crossply $(0 / 90 / 0)$ plate under simple support condition and subjected to sinusoidal loading.

In order to show the performance of the LSE method, the proposed combined model is used for calculating the transverse shear stresses across the thickness of the plate having different parametric variations. The transverse shear stresses are calculated for different problems by using both the direct constitutive relationship as well as by the equilibrium equations used in the LSE method. The abbreviations 'Equil' and 'Const' preceded by an underscore in the legends of the figures indicate quantities evaluated using 3D equilibrium equations and constitutive relations, respectively. Through-the-thickness distribution of transverse shear stresses $\tau_{x z}$ is obtained at the centre of the left edge $(x=0$ and $y=b / 2)$ of the plate, and transverse shear stresses $\tau_{y z}$ are obtained at the centre of the bottom edge $(x=a / 2$ and $y=0)$ of the plate ( $h / a=0.1$ and $h / a=0.25$ ), and are plotted with the 3D elasticity solution Pagano (1970) in Figs 6-7. The figures show that the present results are in good agreement with the elasticity solution.

Although the individual layers possess different orientations, they have equal thickness and material properties as given in Tab.1. This is applicable to all the subsequent problems unless mentioned otherwise. 
Table 2. Normalized maximum deflection $(\bar{w})$ and stresses $\left(\bar{\sigma}_{x x}, \bar{\sigma}_{y y}, \tau_{x z}, \bar{\tau}_{y z}\right)$ at the important points of a simply supported square laminate $(0 / 90 / 0)$ under sinusoidal load of amplitude $q_{0}(b / a=1)$.

\begin{tabular}{|c|c|c|c|c|c|c|c|}
\hline$h / a$ & Reference & Theory & $\begin{array}{c}\bar{w} \\
(a / 2, b / 2,0)\end{array}$ & $\begin{array}{c}\bar{\sigma}_{x x} \\
(a / 2, b / 2, h / 2)\end{array}$ & $\begin{array}{c}\bar{\sigma}_{y y} \\
(a / 2, b / 2, h / 6)\end{array}$ & $\begin{array}{c}\bar{\tau}_{x z}^{\mathrm{a}} \\
(0, b / 2,0)\end{array}$ & $\begin{array}{c}\bar{\tau}_{y z}{ }^{\mathrm{a}} \\
(a / 2,0,0)\end{array}$ \\
\hline & Present $(2 \times 2)^{b}$ & RHSDT & 0.4319 & 0.6194 & 0.2057 & 0.5078 & 0.0783 \\
\hline & Present $(4 \times 4)$ & RHSDT & 0.4300 & 0.5634 & 0.1873 & 0.4313 & 0.0662 \\
\hline & Present $(8 \times 8)$ & RHSDT & 0.4298 & 0.5442 & 0.1810 & 0.4082 & 0.0623 \\
\hline & Present (12x12) & RHSDT & 0.4298 & 0.5403 & 0.1798 & 0.4033 & 0.0615 \\
\hline & Present (16x16) & RHSDT & 0.4298 & 0.5389 & 0.1793 & 0.4014 & 0.0612 \\
\hline & Pagano (1970) & 3D-Elasticity & 0.4347 & 0.5393 & 0.1808 & 0.3947 & 0.0828 \\
\hline & Reddy (1984) & HSDT & 0.4340 & 0.5390 & - & - & 0.0750 \\
\hline \multirow{15}{*}{0.01} & Sheikh and Chakrabarti & & & & & & \\
\hline & $(2003)$ & HSDT & 0.4350 & 0.5496 & 0.1828 & 0.2401 & 0.0749 \\
\hline & Ramesh et al. (2009) & $\mathrm{LWT}^{\mathrm{c}}$ & 0.4349 & 0.5395 & 0.1808 & 0.3921 & 0.0754 \\
\hline & Ramesh et al. (2009) & $\mathrm{TSDT}^{\mathrm{d}}$ & 0.4345 & 0.5394 & 0.1806 & 0.3952 & 0.0835 \\
\hline & Wu et al. (2012) & HSDT & 0.4351 & 0.5521 & 0.1743 & 0.3723 & 0.0667 \\
\hline & Aydogdu (2009) & HSDT & 0.4350 & 0.5389 & 0.1806 & 0.3003 & 0.07905 \\
\hline & $\begin{array}{l}\text { Chakrabarti and Sheikh } \\
\text { (2004) }\end{array}$ & RHSDT & 0.4358 & - & - & - & - \\
\hline & Kulkarni and Kapuria (2007) & TOT & 0.4349 & 0.5403 & 0.1810 & 0.2592 & 0.0752 \\
\hline & Kant and & & & & & & \\
\hline & Swaminathan (2002) & HSDT & 0.4343 & 0.5392 & 0.1807 & - & - \\
\hline & Present $(12 \times 12)$ & RHSDT & 0.7480 & 0.5920 & 0.2874 & 0.3657 & 0.0882 \\
\hline & Pagano (1970) & 3D-Elasticity & 0.7530 & 0.5906 & 0.2845 & 0.3573 & 0.1228 \\
\hline & Reddy (1984) & HSDT & 0.7130 & 0.5684 & - & - & 0.1033 \\
\hline & $\begin{array}{l}\text { Sheikh and Chakrabarti } \\
(2003)\end{array}$ & HSDT & 0.7140 & 0.5806 & 0.2722 & 0.2437 & 0.1015 \\
\hline & Ramesh et al. (2009) & LWT & 0.7535 & 0.5910 & 0.2845 & 0.3576 & 0.1225 \\
\hline \multirow[t]{12}{*}{0.1} & Ramesh et al. (2009) & TSDT & 0.7178 & 0.5850 & 0.2713 & 0.3671 & 0.1178 \\
\hline & Wu et al. (2012) & HSDT & 0.7624 & 0.6331 & 0.2851 & 0.3540 & 0.1257 \\
\hline & Aydogdu (2009) & HSDT & 0.7336 & 0.5780 & 0.2750 & 0.2820 & 0.1110 \\
\hline & $\begin{array}{l}\text { Chakrabarti and Sheikh } \\
\text { (2004) }\end{array}$ & RHSDT & 0.7522 & _- & - & _ & - \\
\hline & Kulkarni and Kapuria (2007) & TOT & 0.7136 & 0.5696 & 0.2697 & 0.2453 & 0.1036 \\
\hline & Kant and Swaminathan (2002) & HSDT & 0.7151 & 0.5836 & 0.2705 & - & - \\
\hline & Liou and Sun (1987) & Hybrid FEM & 0.7546 & 0.5800 & 0.2850 & 0.3670 & 0.1270 \\
\hline & Present $(12 \times 12)$ & RHSDT & 2.0151 & 0.7635 & 0.5771 & 0.2622 & 0.1578 \\
\hline & Pagano (1970) & 3D-Elasticity & 2.0059 & 0.7548 & 0.5341 & 0.2559 & 0.2172 \\
\hline & Reddy (1984) & HSDT & 1.9220 & 0.7345 & - & - & 0.1832 \\
\hline & $\begin{array}{l}\text { Sheikh and Chakrabarti } \\
\text { (2003) }\end{array}$ & HSDT & 1.9230 & 0.7500 & 0.5080 & 0.2023 & 0.1831 \\
\hline & Ramesh et al. (2009) & LWT & 1.9927 & 0.8014 & 0.5336 & 0.2562 & 0.2167 \\
\hline \multirow{7}{*}{0.25} & Ramesh et al. (2009) & TSDT & 1.9136 & 0.7672 & 0.5081 & 0.2809 & 0.2103 \\
\hline & Wu et al. (2012) & HSDT & 2.0557 & 0.8435 & 0.5610 & 0.2569 & 0.2205 \\
\hline & Aydogdu (2009) & HSDT & 1.9856 & 0.7810 & 0.5090 & 0.2260 & 0.1970 \\
\hline & $\begin{array}{l}\text { Chakrabarti and Sheikh } \\
\text { (2004) }\end{array}$ & RHSDT & 1.9502 & - & - & - & - \\
\hline & Kulkarni and Kapuria (2007) & TOT & 1.9248 & 0.7357 & 0.5040 & 0.2029 & 0.1837 \\
\hline & $\begin{array}{l}\text { Kant and Swaminathan } \\
(2002)\end{array}$ & HSDT & 1.8948 & 0.7648 & 0.4939 & - & - \\
\hline & Liou and Sun (1987) & Hybrid FEM & 2.020 & 0.7170 & 0.5170 & 0.2630 & 0.2210 \\
\hline
\end{tabular}

${ }^{a}$ Values of transverse shear stresses obtained from constitutive relation

${ }^{\mathrm{b}}$ Entries inside the parenthesis indicate mesh division

${ }^{\mathrm{c}}$ Layer wise theory

${ }^{\mathrm{d}}$ Third order shear deformation theory 
Table 3. Normalized maximum deflection $(\bar{w})$ and stresses $\left(\bar{\sigma}_{x x}, \bar{\sigma}_{y y}, \tau_{x z}, \bar{\tau}_{y z}\right)$ at the important points of a simply supported rectangular laminate $(0 / 90 / 0)$ under sinusoidal load of amplitude $q_{0}(b / a=3)$.

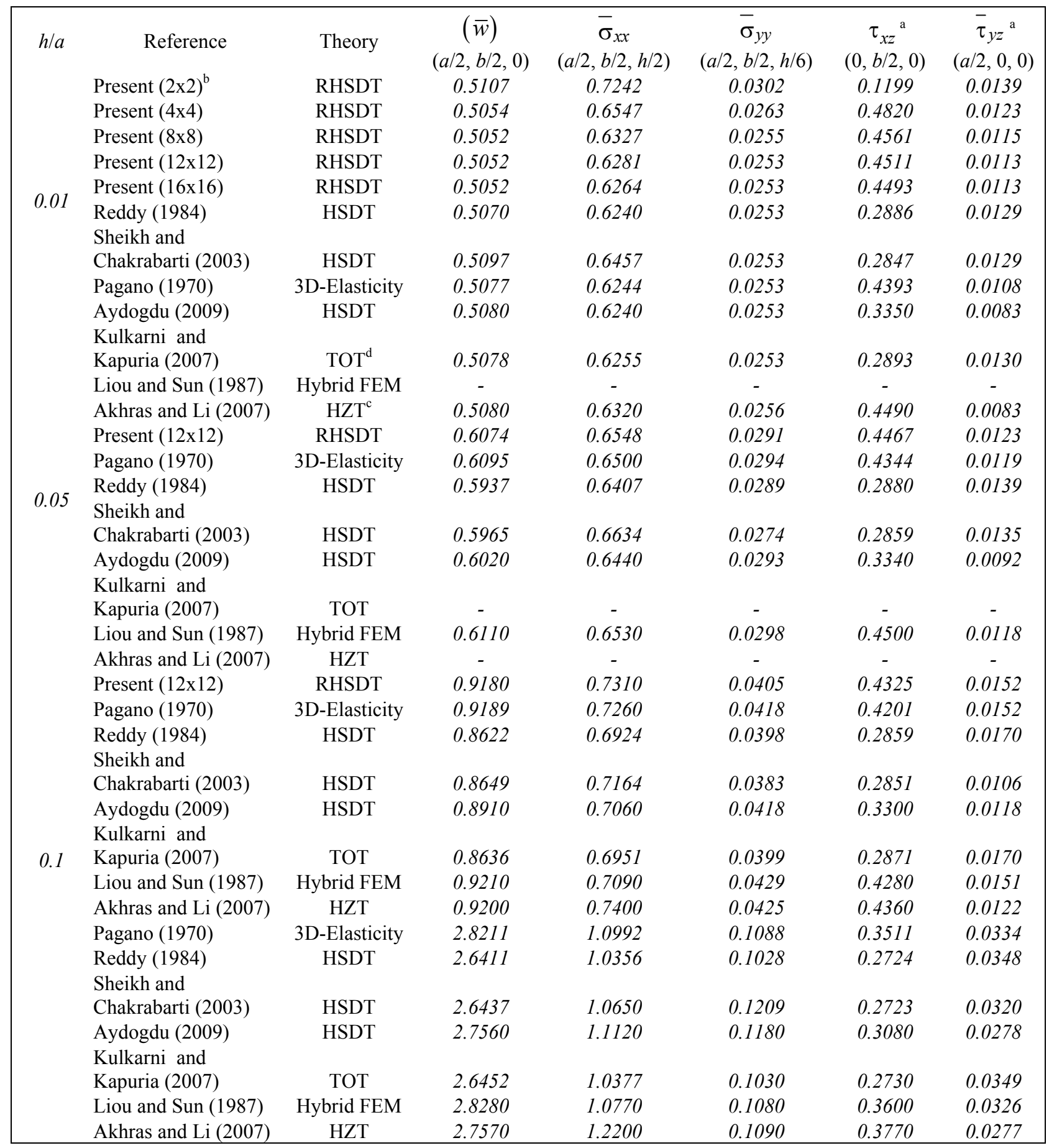

${ }^{\text {a }}$ Values of transverse shear stresses obtained from constitutive relation

${ }^{\mathrm{b}}$ Entries inside the parenthesis indicate mesh division

${ }^{\mathrm{c}}$ Higher order zig-zag theory

${ }^{\mathrm{d}}$ Third order shear deformation theory 

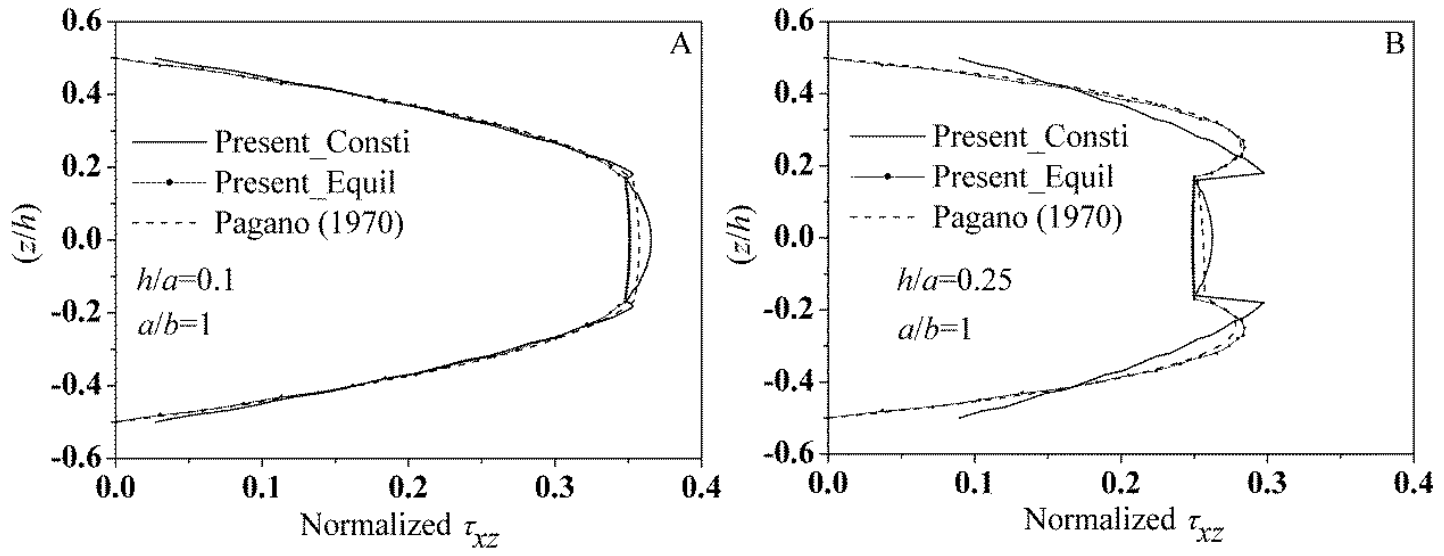

Fig.6. Through thickness variation of normalized transverse shear stress $\tau_{x z}$ (at $x=0, y=b / 2$ ) for rectangular cross-ply $(0 / 90 / 0)$ plate under simple support condition and subjected to sinusoidal loading.
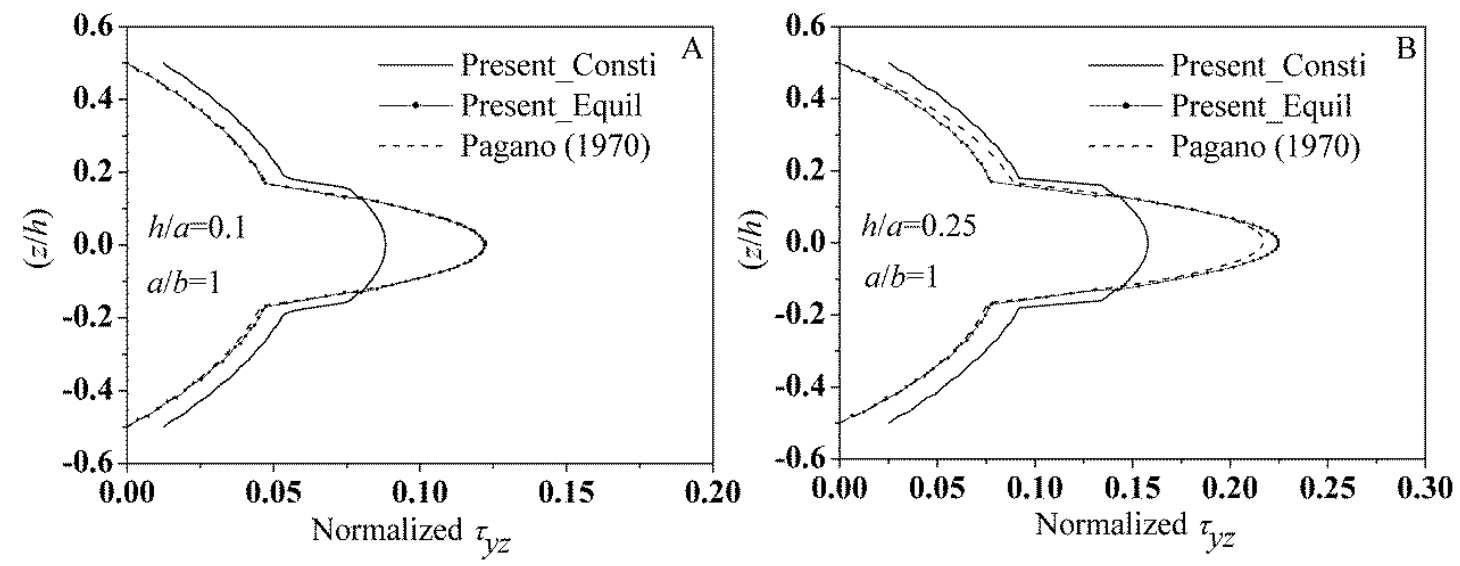

Fig.7. Through thickness variation of normalized transverse shear stress $\tau_{y z}$ (at $x=a / 2, y=0$ ) for rectangular cross-ply $(0 / 90 / 0)$ plate under simple support condition and subjected to sinusoidal loading.

\subsection{Symmetric square sandwich plate $(0 / C / 0)$ having single ply laminated stiff sheets at the faces and subjected to distributed load of sinusoidal variation}

The plate as shown in Fig.3 is simply supported at its four edges and subjected to sinusoidal static load distribution of intensity $q(x, y)=q_{0} \sin (\pi x / a) \sin (\pi y / b)$. The lay-up $(f / c / f)$ has a distribution of thickness among the layers as $(0.10 h / 0.8 h / 0.1 h)$, where $h$ is the total thickness of the plate. The plate is analyzed with the proposed element taking the thickness ratio $(h / a)$ as $0.25,0.2,0.1,0.05$ and 0.01 . The analysis is carried out with the mesh size (Fig.3) of $4 \times 4,8 \times 8$, and $12 \times 12$. The non-dimensional transverse displacement and non-dimensional stresses for different thickness ratios are reported in Tab.4. Using the zigzag theory, the results reported by Pandit et al. (2008) and Singh et al. (2011) incorporating the penalty approach as well as the results reported based on hybrid formulation by Ramtekekar (2002) and using the higher order theory, the result reported by Kant and Swaminathan (2002) are used to check the accuracy of the present model. From Tab.4, the present results are sufficiently close to the results based on the 3-D elasticity solution (Pagano, 1970) mainly for high thickness ratio. 
Table 4. Normalized maximum deflection $(\bar{w})$ and stresses $\left(\bar{\sigma}_{x x}, \bar{\sigma}_{y y}, \bar{\tau}_{x z}, \bar{\tau}_{y z}\right)$ at the important points of a simply supported square sandwich $(0 / C / 0)$ plate under sinusoidal load of amplitude $q_{0}$.

\begin{tabular}{|c|c|c|c|c|c|c|c|c|}
\hline$h / a$ & Reference & $\begin{array}{c}(\bar{w}) \\
(a / 2, b / 2,0)\end{array}$ & $\begin{array}{c}\bar{\sigma}_{y y} \\
(a / 2, b / 2, h / 2)\end{array}$ & $\begin{array}{c}\bar{\sigma}_{y y} \\
(a / 2, b / 2, h / 2)\end{array}$ & $\begin{array}{r}\bar{\tau}_{x z} \text { Const } \\
\quad(0, b / 2,0)\end{array}$ & $\begin{array}{l}\bar{\tau}_{x z} \text { Equil } \\
\quad(0, b / 2,0)\end{array}$ & $\begin{array}{r}\bar{\tau}_{y z} \text { Const } \\
(a / 2,0,0)\end{array}$ & $\begin{array}{r}\bar{\tau}_{y z} \text { Equil } \\
(a / 2,0,0)\end{array}$ \\
\hline & Present $(4 x 4)^{b}$ & 0.8823 & 1.1476 & 0.0638 & 0.3690 & 0.2884 & 0.0372 & 0.0302 \\
\hline & Present (8x8) & 0.8819 & 1.1074 & 0.0617 & 0.3489 & 0.3134 & 0.0349 & 0.0309 \\
\hline & Present (12x12) & 0.8819 & 1.0991 & 0.0613 & 0.3446 & 0.3183 & 0.0345 & 0.0311 \\
\hline & Present (16x16) & 0.8819 & 1.0963 & 0.0611 & 0.3429 & 0.3201 & 0.0343 & 0.0312 \\
\hline 0.01 & Pagano (1970) & 0.8924 & 1.0975 & 0.0550 & 0.3240 & 0.3240 & 0.0297 & 0.0297 \\
\hline & Pandit et al.(2008) & 0.8917 & 1.1093 & 0.0547 & 0.3412 & - & 0.0324 & - \\
\hline & Tu et al. (2010) & 0.8919 & 1.1069 & 0.0573 & 0.3312 & - & 0.3337 & - \\
\hline & Singh et al. (2011) & 0.9017 & 1.1020 & - & 0.4079 & - & - & - \\
\hline & $\begin{array}{l}\text { Kant and Swaminathan } \\
(2002)\end{array}$ & 0.8913 & 1.0990 & 0.0560 & - & - & - & - \\
\hline & Present (12x12) & 1.2128 & 1.1113 & 0.0769 & 0.3374 & 0.3118 & 0.0415 & 0.0374 \\
\hline & Pagano (1970) & 1.2264 & 1.1098 & 0.0701 & 0.3174 & 0.3174 & 0.0361 & 0.0361 \\
\hline 0.05 & Pandit et al.(2008) & 1.2254 & 1.1055 & 0.0694 & 0.3342 & - & 0.0392 & - \\
\hline & Singh et al. (2011) & 1.2424 & 1.1161 & - & 0.3429 & - & - & - \\
\hline & Ramtekekar et al. (2002) & - & 1.1150 & 0.0700 & 0.3170 & - & 0.0360 & - \\
\hline & $\begin{array}{l}\text { Kant and Swaminathan } \\
(2002)\end{array}$ & 1.1933 & 1.1110 & 0.0705 & - & - & - & - \\
\hline & Present $(12 \times 12)$ & 2.1786 & 1.1539 & 0.1184 & 0.3185 & 0.2947 & 0.0598 & 0.0537 \\
\hline & Pagano (1970) & 2.2004 & 1.1531 & 0.1104 & 0.2998 & 0.2998 & 0.0527 & 0.0527 \\
\hline \multirow{5}{*}{0.1} & Pandit et al.(2008) & 2.2002 & 1.1483 & 0.1086 & 0.31580 & - & 0.0570 & - \\
\hline & Tu et al. (2010) & 2.2027 & 1.1466 & 0.1105 & 0.3181 & - & 0.0532 & - \\
\hline & Singh et al. (2011) & 2.2389 & 1.1530 & - & 0.3000 & - & - & - \\
\hline & Ramtekekar et al. (2002) & - & 1.159 & 0.1110 & 0.3030 & - & 0.0550 & - \\
\hline & $\begin{array}{l}\text { Kant and Swaminathan } \\
(2002)\end{array}$ & 2.0798 & 1.1523 & 0.1100 & - & - & - & - \\
\hline \multirow[t]{5}{*}{0.2} & Present $(12 \times 12)$ & 5.4464 & 1.3617 & 0.2216 & 0.2729 & 0.2530 & 0.1025 & 0.0916 \\
\hline & Pagano (1970) & 5.4746 & 1.3704 & 0.2094 & 0.2569 & 0.2569 & 0.0918 & 0.0918 \\
\hline & Present (12x12) & 7.5873 & 1.5316 & 0.2674 & 0.2538 & 0.2354 & 0.1192 & 0.1063 \\
\hline & Pagano (1970) & 7.5962 & 1.5121 & 0.2595 & 0.2387 & 0.2387 & 0.1072 & 0.1072 \\
\hline & Pandit et al.(2008) & 7.6552 & 1.5218 & 0.2506 & 0.2520 & - & 0.1156 & - \\
\hline 0.25 & Tu et al. (2010) & 7.5610 & 1.5518 & 0.2483 & 0.1184 & - & 0.2447 & - \\
\hline & Singh et al. (2011) & 7.8556 & 1.5480 & - & 0.2611 & - & - & - \\
\hline & Ramtekekar et al. (2002) & - & 1.570 & 0.2600 & 0.2400 & - & 0.1080 & - \\
\hline & $\begin{array}{l}\text { Kant and Swaminathan } \\
(2002)\end{array}$ & 7.0551 & 1.5137 & 0.2648 & - & - & - & - \\
\hline
\end{tabular}

${ }^{\mathrm{b}}$ Entries inside the parenthesis indicate mesh division 

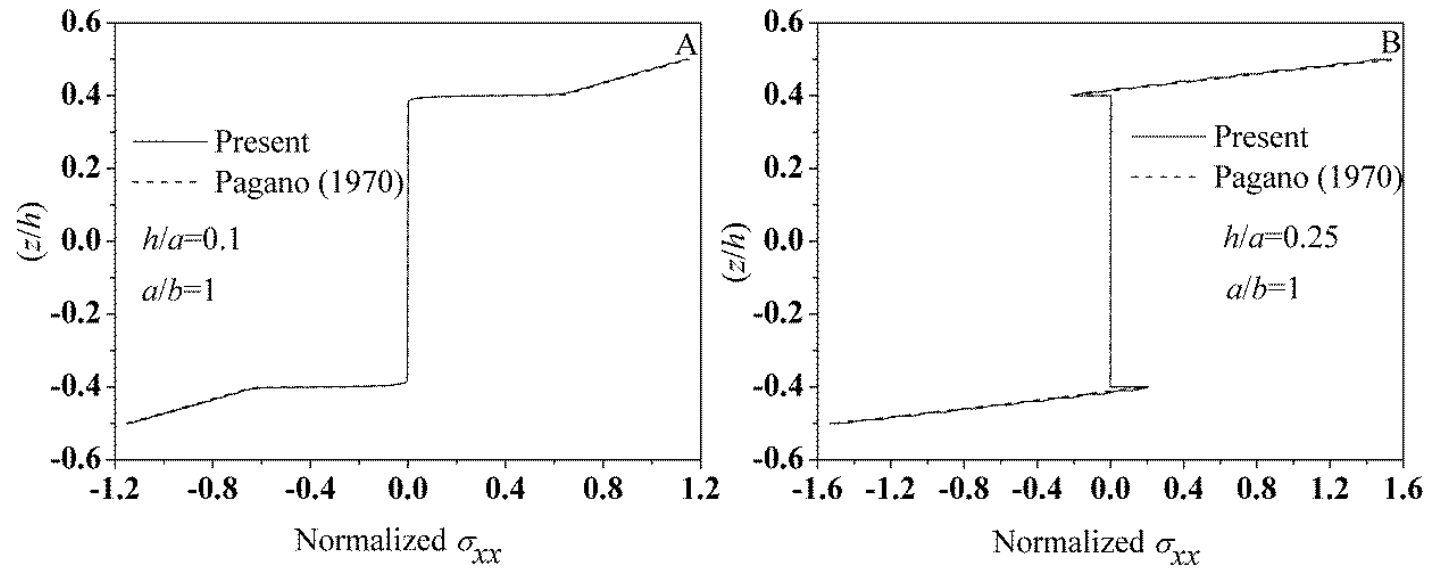

Fig.8. Through thickness variation of normalized in-plane stress $\sigma_{x x}$ (at $x=a / 2, y=b / 2$ ) for square sandwich $(0 /$ core $/ 0)$ plate under simple support condition and subjected to sinusoidal loading.
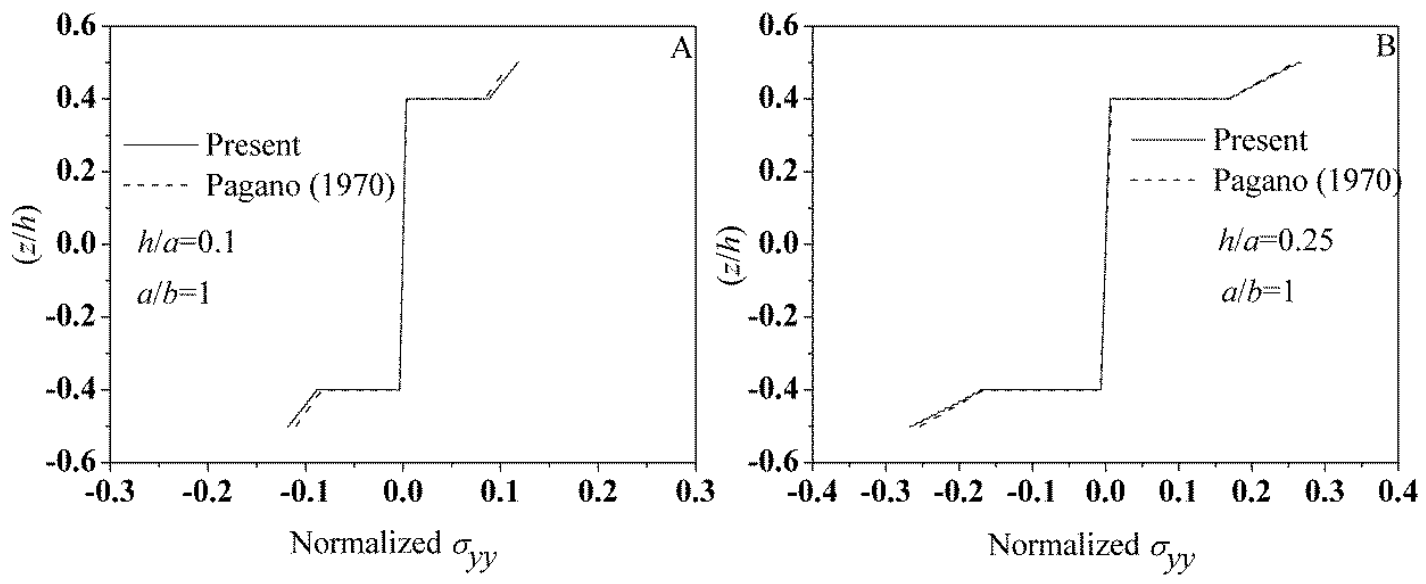

Fig.9. Through thickness variation of normalized in-plane stress $\sigma_{y y}$ (at $x=a / 2, y=b / 2$ ) for square sandwich $(0 /$ core $/ 0)$ plate under simple support condition and subjected to sinusoidal loading.
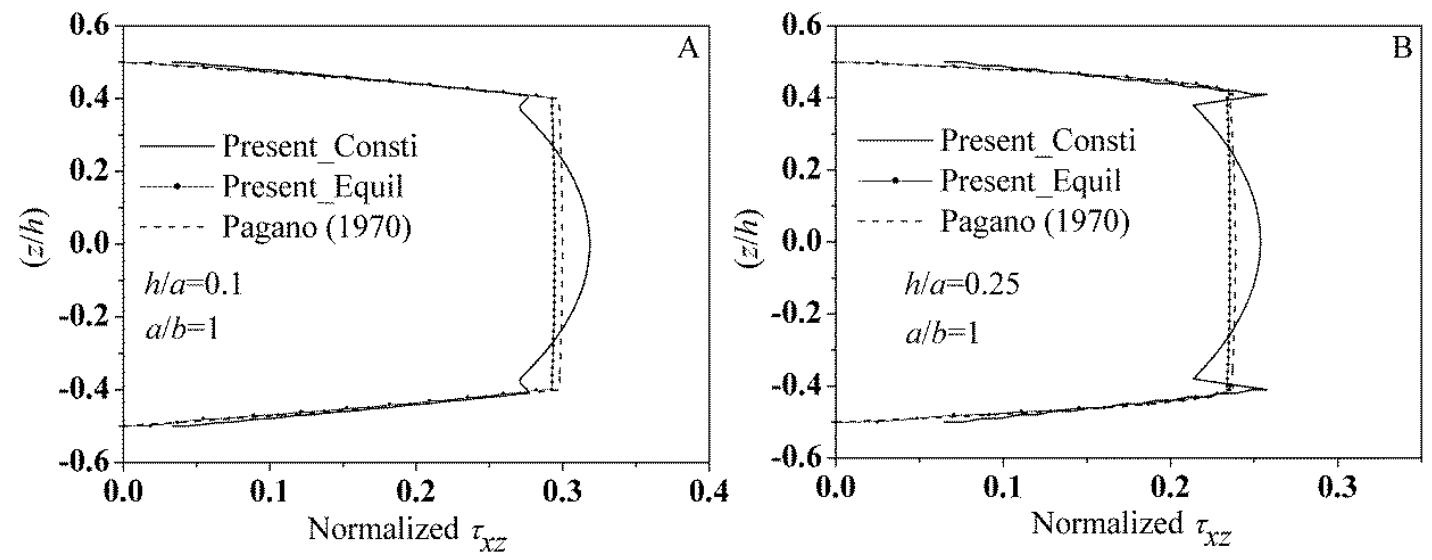

Fig.10. Through thickness variation of normalized transverse shear stress $\tau_{x z}$ (at $x=0, y=b / 2$ ) for square sandwich $(0 /$ core $/ 0)$ plate under simple support condition and subjected to sinusoidal loading. 

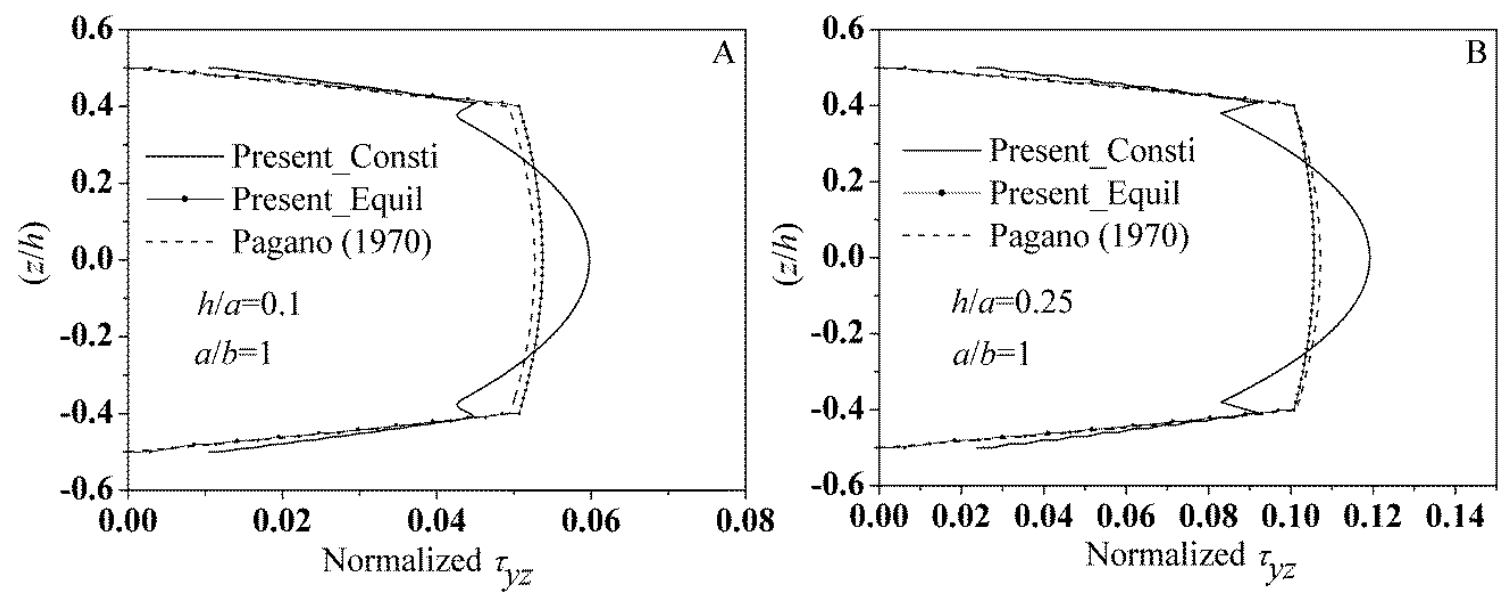

Fig.11. Through thickness variation of normalized transverse shear stress $\tau_{y z}$ (at $x=a / 2, y=0$ ) for square sandwich $(0 /$ core $/ 0)$ plate under simple support condition and subjected to sinusoidal loading.

Now, the through-the-thickness variations of normalized in-plane normal stresses $\left(\sigma_{x x}, \sigma_{y y}\right)$ are obtained at the plate center $(a / 2, b / 2)$ in the present analysis (mesh size: $12 \times 12, b / a=1, h / a=0.1$ and $h / a=0.25$ ), and are plotted with the 3D elasticity solution (Pagano, 1970) in Figs 8-9. The figures show that the present results are in excellent agreement with the elasticity solution.

Through-the-thickness distribution of transverse shear stresses $\tau_{x z}$ is obtained at the centre of the left edge ( $x=0$ and $y=b / 2)$ of the plate, and transverse shear stresses $\tau_{y z}$ are obtained at the centre of the bottom edge ( $x=a / 2$ and $y=0$ ) of the plate (mesh size: $12 \times 12, b / a=1, h / a=0.1$ and $h / a=0.25$ ), are plotted with the 3D elasticity solution (Pagano, 1970) in Figs 10-11. The figures show that the present results are in good agreement with the elasticity solution.

\subsection{Un-symmetric laminated square sandwich plate $(0 / 90 / C / 0 / 90)$ subjected to distributed load of sinusoidal variation}

An unsymmetrical square laminated sandwich plate $(0 / 90 / C / 0 / 90)$ is considered for the analysis in this example under the sinusoidal loading of intensity $q(x, y)=q_{0} \sin (\pi x / a) \sin (\pi y / b)$. In the present problem, the thickness of the core is taken as $0.8 h$, while that of each ply in the laminated stiff sheets is $0.05 h$, where $h$ (= 1 inch) is the overall thickness of the plate. Material properties used for the core and each laminated face sheets are given in Tab.1. The study has been made for three types of boundary conditions. These are: SSSS, i.e., all the four edges are simply supported, CCCC, i.e., all the four edges are clamped and SCSC, i.e., two opposite edges are simply supported and other two edges clamped. The values of the non-dimensional transverse displacement, in-plane normal and transverse shear stresses are presented in Tab.6 for different values of the thickness ratio $(h / a)$ ranging from 0.01 to 0.50 .

The percentage increase in transverse deformation for the higher thickness ratios is much higher than that of lower thickness ratios for both boundary conditions. This is due to the effects of transverse flexibility of the core and shear deformation, which are more pronounced at higher thickness ratios. As the thickness of the core is $0.8 h$, so the core compressibility plays a very important role which is reflected in Tab.5. The results are in good agreement with the results reported by Pandit et al. (2008) and Singh et al. (2011). 
Table 5. Normalized maximum deflection $(\bar{w})$ and stresses $\left(\bar{\sigma}_{x x}, \bar{\sigma}_{y y}, \bar{\tau}_{x z}, \bar{\tau}_{y z}\right)$ at the important points of an un-symmetric square sandwich plate $(0 / 90 / C / 0 / 90)$ under sinusoidal load of amplitude $q_{0}$.

\begin{tabular}{|c|c|c|c|c|c|c|c|c|}
\hline \multicolumn{9}{|c|}{ Boundary condition: SSSS } \\
\hline \multirow[t]{2}{*}{$h / a$} & Reference & $(\bar{w})$ & $\bar{\sigma}_{x x}$ & $\bar{\sigma}_{y y}$ & $\bar{\tau}_{x z}$ Consti & $\bar{\tau}_{x z}$ Equil & $\bar{\tau}_{y z}$ Const & $\bar{\tau}_{y z}$ Equil \\
\hline & & $(a / 2, b / 2,0)$ & $(a / 2, b / 2, h / 2)$ & $(a / 2, b / 2, h / 4)$ & $(0, b / 2,0)$ & $(0, b / 2,0)$ & $(a / 2,0,0)$ & $(a / 2,0,0)$ \\
\hline \multirow[t]{2}{*}{0.01} & Present & 0.8782 & 1.0820 & 1.0536 & 0.1878 & 0.1751 & 0.1812 & 0.1734 \\
\hline & Pagano (1970) & 0.8888 & 1.0404 & 1.0500 & 0.1773 & 0.1773 & 0.1773 & 0.1773 \\
\hline \multirow{3}{*}{0.10} & Present & 1.7177 & 1.1270 & 1.0769 & 0.1909 & 0.1741 & 0.1883 & 0.1714 \\
\hline & Pagano (1970) & 1.7272 & 1.1002 & 1.0817 & 0.1770 & 0.1770 & 0.1770 & 0.1770 \\
\hline & Singh et al. (2011) & 1.7420 & - & - & - & - & - & - \\
\hline \multirow[t]{2}{*}{0.25} & Present & 6.1342 & 1.4086 & 1.3490 & 0.1901 & 0.1718 & 0.1888 & 0.1692 \\
\hline & Pagano (1970) & 6.1105 & 1.3770 & 1.3697 & 0.1756 & 0.1756 & 0.1751 & 0.1751 \\
\hline \multicolumn{9}{|c|}{ Boundary condition: CCCC } \\
\hline \multirow{3}{*}{0.01} & Present & 0.2279 & 0.4392 & 0.4102 & 0.2198 & 0.2078 & 0.2190 & 0.2027 \\
\hline & Pandit et al. (2008) & 0.2286 & 0.4270 & - & 0.2189 & - & 0.2189 & - \\
\hline & Singh et al. (2011) & 0.2260 & 0.4283 & - & 0.2348 & - & - & - \\
\hline \multirow{3}{*}{0.05} & Present & 0.4299 & 0.4388 & 0.4116 & 0.1661 & 0.1804 & 0.1661 & 0.1770 \\
\hline & Pandit et al. (2008) & 0.4296 & 0.4275 & - & 0.1828 & - & 0.1828 & - \\
\hline & Singh et al. (2011) & 0.4462 & 0.4293 & - & 0.2004 & - & - & - \\
\hline \multirow{3}{*}{0.10} & Present & 1.0513 & 0.4720 & 0.4450 & 0.1380 & 0.1567 & 0.1383 & 0.1544 \\
\hline & Pandit et al.(2008) & 1.0489 & 0.4597 & - & 0.1587 & - & 0.1586 & - \\
\hline & Singh et al. (2011) & 1.0213 & 0.4621 & - & 0.1651 & - & - & - \\
\hline \multirow{3}{*}{0.20} & Present & 3.4741 & 0.6280 & 0.5985 & 0.1240 & 0.1313 & 0.1242 & 0.1296 \\
\hline & Pandit et al. (2008) & 3.4521 & 0.6170 & - & 0.1396 & - & 0.1394 & - \\
\hline & Singh et al. (2011) & 3.3421 & 0.6022 & - & 0.1422 & - & - & - \\
\hline 0.25 & Present & 5.2470 & 0.7442 & 0.7127 & 0.1228 & 0.1236 & 0.1231 & 0.1218 \\
\hline \multirow[t]{3}{*}{0.50} & Present & 19.1560 & 1.6275 & 1.5895 & 0.1264 & 0.1041 & 0.1265 & 0.1021 \\
\hline & Pandit et al. (2008) & 18.3454 & 1.8156 & 0.1902 & 0.1227 & - & 0.1217 & - \\
\hline & Singh et al. (2011) & 18.3450 & 1.8150 & - & 0.1325 & - & - & - \\
\hline \multicolumn{9}{|c|}{ Boundary condition: SCSC } \\
\hline \multirow{3}{*}{0.01} & Present & 0.3451 & 0.4279 & 0.6303 & 0.0782 & 0.0730 & 0.3061 & 0.2895 \\
\hline & Pandit et al. (2008) & 0.3453 & 0.4077 & - & 0.0778 & - & 0.3086 & - \\
\hline & Singh et al. (2011) & 0.3920 & 0.5986 & - & 0.0944 & - & - & - \\
\hline \multirow{3}{*}{0.05} & Present & 0.6053 & 0.6069 & 0.5847 & 0.1075 & 0.0985 & 0.2288 & 0.2458 \\
\hline & Pandit et al.(2008) & 0.6052 & 0.5850 & - & 0.1061 & - & 0.2527 & - \\
\hline & Singh et al. (2011) & 0.6080 & 0.6138 & - & 0.1542 & - & - & - \\
\hline \multirow{3}{*}{0.10} & Present & 1.3039 & 0.8586 & 0.5514 & 0.1437 & 0.1308 & 0.1711 & 0.1918 \\
\hline & Pandit et al. (2008) & 1.3026 & 0.8310 & - & 0.1418 & - & 0.1967 & - \\
\hline & Singh et al. (2011) & 1.3092 & 0.7392 & - & 0.1523 & - & - & - \\
\hline \multirow{3}{*}{0.20} & Present & 3.8288 & 1.1786 & 0.6554 & 0.1708 & 0.1545 & 0.1369 & 0.1433 \\
\hline & Pandit et al. (2008) & 3.8087 & 1.1415 & - & 0.1683 & - & 0.1539 & - \\
\hline & Singh et al. (2011) & 3.8500 & 1.0189 & - & 0.1620 & - & - & - \\
\hline 0.25 & Present & 5.6638 & 1.3197 & 0.7647 & 0.1747 & 0.1576 & 0.1327 & 0.1319 \\
\hline \multirow{3}{*}{0.50} & Present & 20.3055 & 2.1925 & 1.6834 & 0.1744 & 0.1543 & 0.1338 & 0.1086 \\
\hline & Pandit et al.(2008) & 19.5512 & 2.3071 & - & 0.1691 & - & 0.1296 & - \\
\hline & Singh et al. (2011) & 19.5800 & 2.4028 & - & 0.1721 & - & - & - \\
\hline
\end{tabular}


Table 6. Normalized maximum deflection $(\bar{w})$ and stresses $\left(\bar{\sigma}_{x x}, \bar{\sigma}_{y y}, \bar{\tau}_{x z}, \bar{\tau}_{y z}\right)$ at the important points of a simply supported square sandwich plate with angle-ply laminated faces $(\theta / \theta+90 / C / \theta / \theta+90)$ under uniformly distributed load.

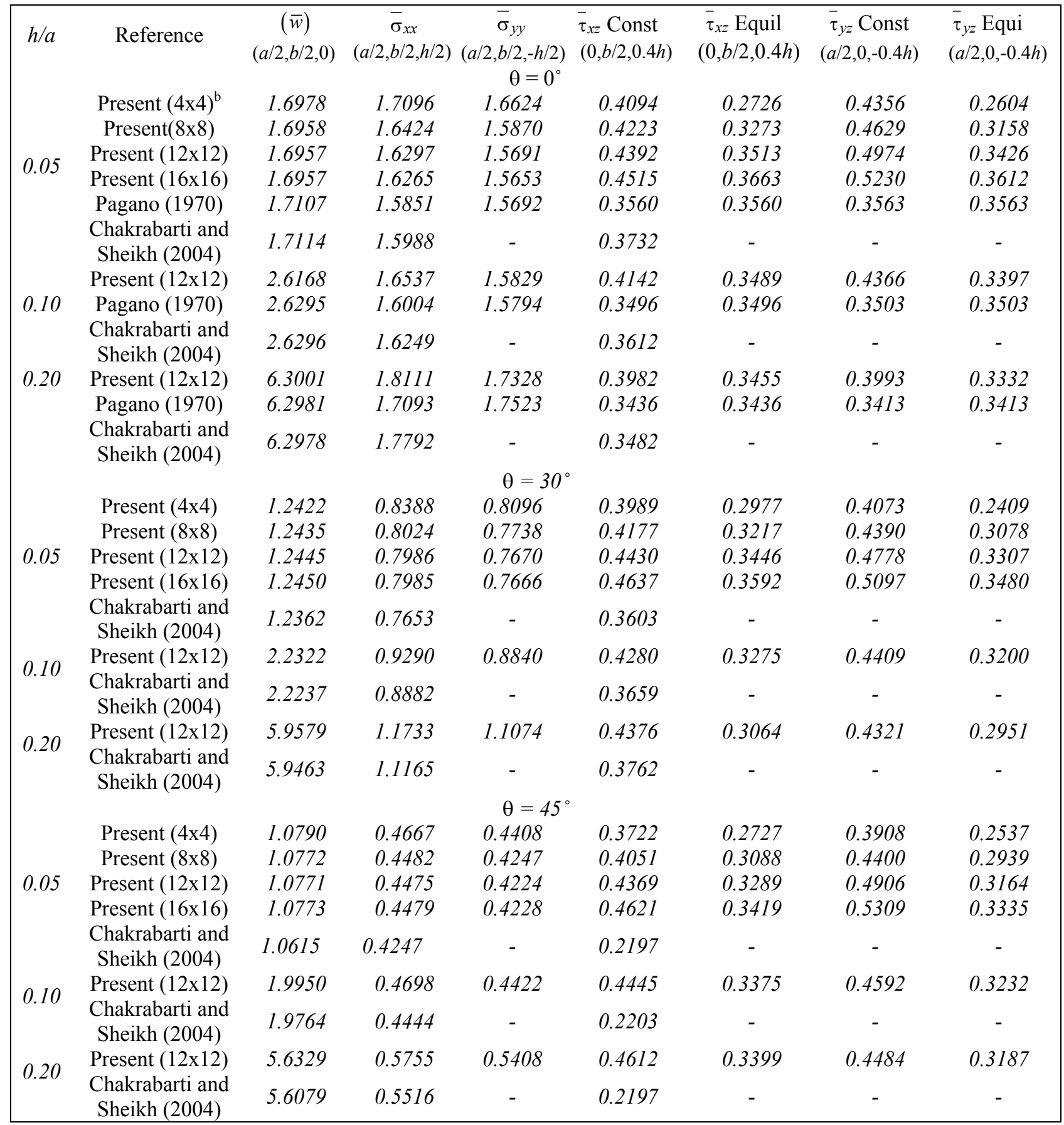

${ }^{\mathrm{b}}$ Entries inside the parenthesis indicate mesh division 


\subsection{Square sandwich plate $(\theta / \theta+90 / C / \theta / 90+\theta)$ having angle-ply laminated stiff sheets at the two faces subjected to uniformly distributed load}

The plate (Fig.3, $b / a=1$ ) is simply supported at its for edges and subjected to a uniformly distributed load of intensity $q$. For this plate, the thickness distribution for the core and the individual ply in the laminate sheets is identical to that of the plate taken in Problem 3.4. The whole plate is analyzed with mesh size of $4 \times 4,8 \times 8,12 \times 12,16 \times 16$ taking $h / a=0.05,0.1$ and 0.2 , and $\theta=0^{\circ}, 30^{\circ}, 45^{\circ}$. The values of deflection $w$ at the midpoint of the plate $(x=a / 2, y=a / 2$ and $z=0)$, the in-plane normal stresses $\sigma_{x x}$ at $x=a / 2, y=a / 2$ and $z=h / 2$ of the plate and $\sigma_{y y}$ at $x=a / 2, y=a / 2$ and $z=-h / 2$ of the plate, the transverse shear stresses $\tau_{x z}$ at the centre of the left edge $(x=0, y=a / 2$ and $z=0.4 h)$ of the plate and the transverse shear stresses $\tau_{y z}$ at the centre of the bottom edge $(x=a / 2, y=0$ and $z=-0.4 h)$ of the plate obtained in the present analysis are presented in Tab.6. The present results corresponding to $\theta=0^{\circ}$ are compared with the $3 \mathrm{D}$ elasticity solution, which validates the present results up to a certain extent.

\subsection{Square sandwich plate $(0 / 90 / c / 0 / 90)$ having angle-ply laminated stiff sheets at the two faces subjected to uniformly distributed load}

The skew sandwich plate, as shown in Fig. 12 is analyzed with the proposed element taking $h / a=0.1$ and the skew angle $\alpha=0^{\circ}, 15^{\circ}, 30^{\circ}, 45^{\circ}$ and $60^{\circ}$. In the present study, the boundary condition at four sides is taken as simply supported in one case, while it is clamped in the other case. The thickness distribution of the different layer is identical to that used in the previous example. The whole plate is taken in the analysis and carried out with mesh sizes (Fig.12) of $4 \times 4,8 \times 8,12 \times 12,16 \times 16$ and $20 \times 20$. As the sides BC and AD (Fig.12) are inclined to the global axis system $(x-y)$, the DOF of the nodes on these two lines are transformed to express them in the local axis system along $\left(x^{\prime}-y^{\prime}\right)$ as shown in Fig.12. The transformation is essential for simply supported boundaries, which is one of the cases considered in the present problem. The value of $\bar{w}$ at the plate center, $\bar{\sigma}_{x x}$ at $x=(a+b \sin \alpha) / 2, y=(b \cos \alpha) / 2, z=h / 2$ (Fig.12), and $\bar{\tau}_{y z}$ at $x=a / 2, y=0, z=0.4 h$ obtained in the present analysis are presented in Tab.7. For the skew angle $(\alpha)$ of $0^{\circ}$, the present results are compared with the 3D elasticity solution (Pagano, 1970) which shows a good correlation between them and for skew angles $(\alpha)$ of $15^{\circ}$, $30^{\circ}, 45^{\circ}$ and $60^{\circ}$, the results are in good agreement with the results reported by Chakrabarti and Sheikh (2004).

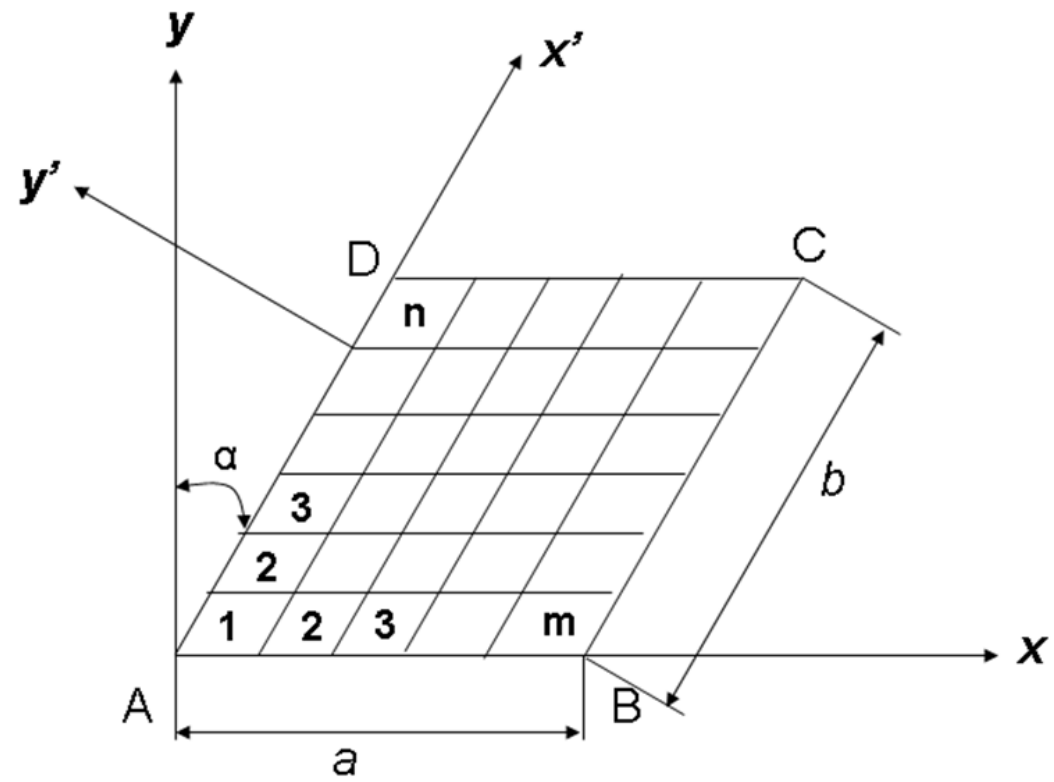

Fig.12. Rectangular skew plate having a mesh of $m \times n$. 
Table 7. Normalized maximum deflection $(\bar{w})$ and stresses $\left(\bar{\sigma}_{x x}, \bar{\sigma}_{y y}, \bar{\tau}_{x z}, \bar{\tau}_{y z}\right)^{\mathrm{a}}$ at the important points of a skew sandwich plate with laminated faces $(0 / 90 / C / 90 / 0)$ under Uniformly Distributed Load $(h / a=0.1)$.

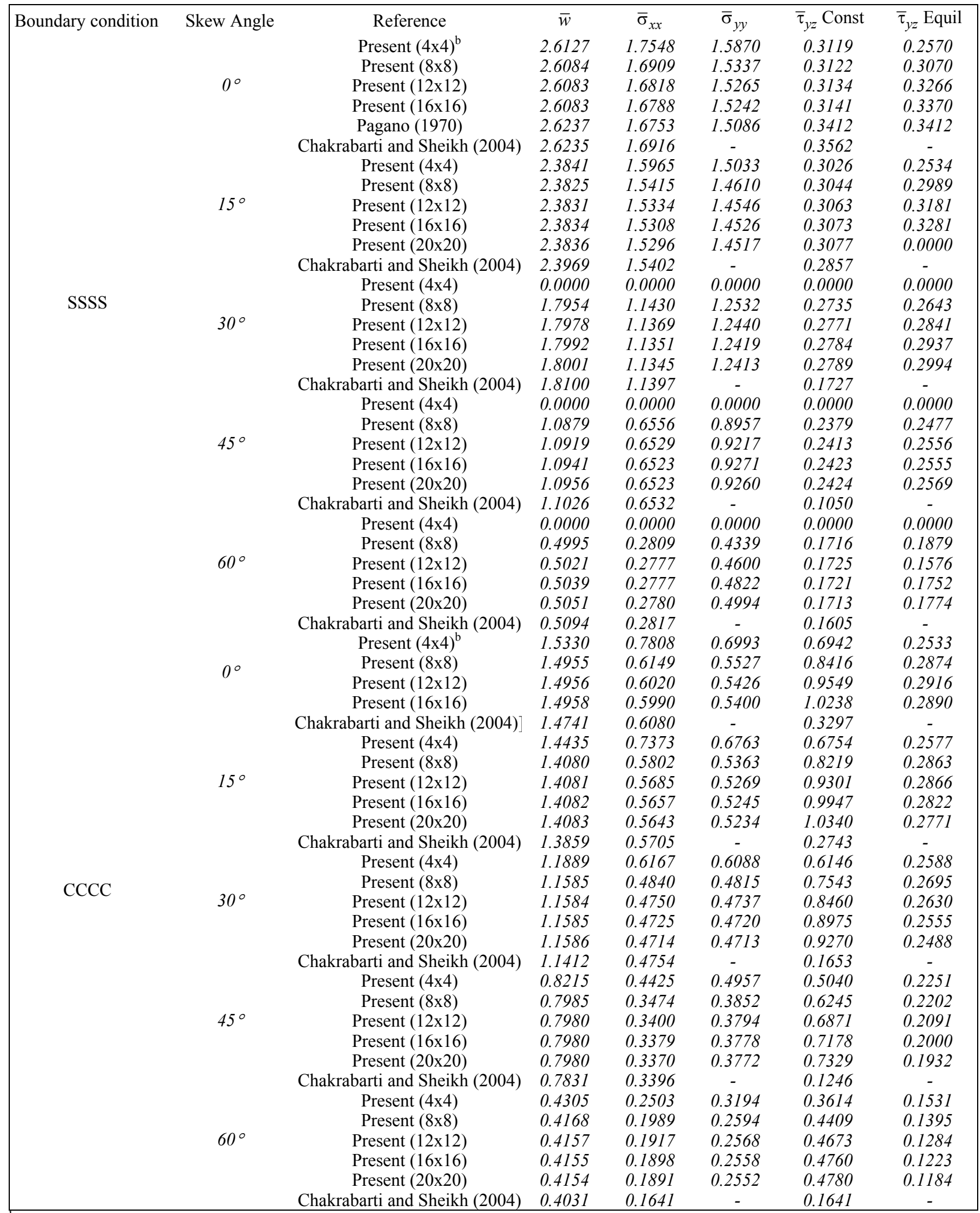

\footnotetext{
${ }^{\mathrm{b}}$ Entries inside the parenthesis indicate mesh division
} 


\section{Conclusion}

In this paper an improved $C^{0}$ plate finite element (FE) model has been developed for the static analysis of a laminated soft core sandwich plate based on the refined higher order shear deformation theory (RHSDT) with a least square error (LSE) method to accurately calculate the deflections as well as stresses for different problems of composite and sandwich laminates. The proposed analysis is done in two stages. The FE model based on the RHSDT is used first which calculates the deflections and in-plane stresses more accurately than any other existing 2D plate theory. The LSE method is then utilized to predict the transverse shear stresses accurately from the results of deflections and in-plane stresses obtained by the FE analysis based on the RHSDT at the first stage of the analysis. It is also interesting to note that the displacement fields and the corresponding stress fields used in the RHSDT and in the LSE method used in the proposed combined model perfectly matches with each other which is not so in the case of the combination of the HSDT with LSE method. Therefore, the proposed combined model may be recommended as the most efficient $2 \mathrm{D}$ method to calculate the deflections as well as stresses (in-plane and transverse) accurately for all types of composites and sandwich laminates.

\section{Acknowledgements}

Financial support obtained for the present work from the Department of Science and Technology, New Delhi, India under the grant DST-536-CED is gratefully acknowledged.

\section{Appendix A}

$$
\begin{aligned}
& b_{1}=1+A_{11} z^{2}+A_{31} z^{3}+\sum_{i=1}^{n u-1} A_{(i+4), l}\left(z-z_{i u}\right) H\left(z-z_{i u}\right)+\sum_{j=1}^{n l-1} A_{(n u+3+j), l}\left(z-z_{j l}\right) H\left(-z+z_{j l}\right), \\
& b_{2}=A_{12} z^{2}+A_{32} z^{3}+\sum_{i=1}^{n u-1} A_{(i+4), 2}\left(z-z_{i u}\right) H\left(z-z_{i u}\right)+\sum_{j=1}^{n l-1} A_{(n u+3+j), 2}\left(z-z_{j l}\right) H\left(-z+z_{j l}\right), \\
& b_{3}=z+A_{13} z^{2}+A_{33} z^{3}+\sum_{i=1}^{n u-1} A_{(i+4), 3}\left(z-z_{i u}\right) H\left(z-z_{i u}\right)+\sum_{j=1}^{n l-1} A_{(n u+3+j), 3}\left(z-z_{j l}\right) H\left(-z+z_{j l}\right), \\
& b_{4}=A_{14} z^{2}+A_{34} z^{3}+\sum_{i=1}^{n u-1} A_{(i+4), 4}\left(z-z_{i u}\right) H\left(z-z_{i u}\right)+\sum_{j=1}^{n l-1} A_{(n u+3+j), 4}\left(z-z_{j l}\right) H\left(-z+z_{j l}\right), \\
& b_{5}=A_{15} z^{2}+A_{35} z^{3}+\sum_{i=1}^{n u-1} A_{(i+4), 5}\left(z-z_{i u}\right) H\left(z-z_{i u}\right)+\sum_{j=1}^{n l-1} A_{(n u+3+j), 5}\left(z-z_{j l}\right) H\left(-z+z_{j l}\right), \\
& b_{6}=A_{16} z^{2}+A_{36} z^{3}+\sum_{i=1}^{n u-1} A_{(i+4), 6}\left(z-z_{i u}\right) H\left(z-z_{i u}\right)+\sum_{j=1}^{n l-1} A_{(n u+3+j), 6}\left(z-z_{j l}\right) H\left(-z+z_{j l}\right), \\
& b_{7}=A_{17} z^{2}+A_{37} z^{3}+\sum_{i=1}^{n u-1} A_{(i+4), 7}\left(z-z_{i u}\right) H\left(z-z_{i u}\right)+\sum_{j=1}^{n l-1} A_{(n u+3+j), 7}\left(z-z_{j l}\right) H\left(-z+z_{j l}\right), \\
& b_{8}=A_{18} z^{2}+A_{38} z^{3}+\sum_{i=1}^{n u-1} A_{(i+4), 8}\left(z-z_{i u}\right) H\left(z-z_{i u}\right)+\sum_{j=1}^{n l-1} A_{(n u+3+j), 8}\left(z-z_{j l}\right) H\left(-z+z_{j l}\right),
\end{aligned}
$$




$$
\begin{aligned}
& c_{1}=A_{21} z^{2}+A_{41} z^{3}+\sum_{i=1}^{n u-1} A_{(n u+n l+2+i), l}\left(z-z_{i u}\right) H\left(z-z_{i u}\right)+\sum_{j=1}^{n l-1} A_{(2 n u+n l+1+j), 1}\left(z-z_{j l}\right) H\left(-z+z_{j l}\right), \\
& c_{2}=1+A_{22} z^{2}+A_{42} z^{3}+\sum_{i=1}^{n u-1} A_{(n u+n l+2+i), 2}\left(z-z_{i u}\right) H\left(z-z_{i u}\right)+\sum_{j=1}^{n l-1} A_{(2 n u+n l+1+j), 2}\left(z-z_{j l}\right) H\left(-z+z_{j l}\right), \\
& c_{3}=A_{23} z^{2}+A_{43} z^{3}+\sum_{i=1}^{n u-1} A_{(n u+n l+2+i), 3}\left(z-z_{i u}\right) H\left(z-z_{i u}\right)+\sum_{j=1}^{n l-1} A_{(2 n u+n l+1+j), 3}\left(z-z_{j l}\right) H\left(-z+z_{j l}\right), \\
& c_{4}=z+A_{24} z^{2}+A_{44} z^{3}+\sum_{i=1}^{n u-1} A_{(n u+n l+2+i), 4}\left(z-z_{i u}\right) H\left(z-z_{i u}\right)+\sum_{j=1}^{n l-1} A_{(2 n u+n l+1+j), 4}\left(z-z_{j l}\right) H\left(-z+z_{j l}\right), \\
& c_{5}=A_{25} z^{2}+A_{45} z^{3}+\sum_{i=1}^{n u-1} A_{(n u+n l+2+i), 5}\left(z-z_{i u}\right) H\left(z-z_{i u}\right)+\sum_{j=1}^{n l-1} A_{(2 n u+n l+l+j), 5}\left(z-z_{j l}\right) H\left(-z+z_{j l}\right), \\
& c_{6}=A_{26} z^{2}+A_{46} z^{3}+\sum_{i=1}^{n u-1} A_{(n u+n l+2+i), 6}\left(z-z_{i u}\right) H\left(z-z_{i u}\right)+\sum_{j=1}^{n l-1} A_{(2 n u+n l+1+j), 6}\left(z-z_{j l}\right) H\left(-z+z_{j l}\right), \\
& c_{8}=A_{28} z^{2}+A_{48} z^{3}+\sum_{i=1}^{n u-1} A_{(n u+n l+2+i), 8}\left(z-z_{i u}\right) H\left(z-z_{i u}\right)+\sum_{j=1}^{n l-1} A_{(2 n u+n l+l+j), 8}\left(z-z_{j l}\right) H\left(-z+z_{j l}\right) \\
& c_{7}=A_{27} z^{2}+A_{47} z^{3}+\sum_{i=1}^{n u-1} A_{(n u+n l+2+i), 7}\left(z-z_{i u}\right) H\left(z-z_{i u}\right)+\sum_{j=1}^{n l-1} A_{(2 n u+n l+1+j), 7}\left(z-z_{j l}\right) H\left(-z+z_{j l}\right),
\end{aligned}
$$

\section{Appendix B}

Elements of matrix $H$,

$$
\begin{aligned}
& {[H]=\left[\begin{array}{cccccccccccccccc}
0 & 0 & 0 & 0 & 0 & 0 & 0 & 0 & 0 & 0 & 0 & b_{1} & 0 & b_{2} & 0 & 0 \\
0 & 0 & 0 & 0 & 0 & 0 & 0 & 0 & 0 & 0 & 0 & 0 & c_{1} & 0 & c_{2} & 0 \\
0 & 0 & d_{2} & 0 & 0 & 0 & 0 & d_{1} & 0 & 0 & d_{3} & 0 & 0 & 0 & 0 & 0 \\
0 & 0 & 0 & 0 & 0 & 0 & 0 & 0 & 0 & 0 & 0 & c_{1} & b_{1} & c_{2} & b_{2} & 0 \\
a_{1} & a_{2} & 0 & a_{3} & a_{4} & a_{5} & a_{6} & 0 & a_{7} & a_{8} & 0 & 0 & 0 & 0 & 0 & l_{2} \\
e_{1} & e_{2} & 0 & e_{3} & e_{4} & e_{5} & e_{6} & 0 & e_{7} & e_{8} & 0 & 0 & 0 & 0 & 0 & 0
\end{array}\right.} \\
& \left.\begin{array}{lllllllllllllllll}
0 & b_{3} & 0 & b_{4} & 0 & b_{5} & 0 & b_{6} & 0 & 0 & 0 & b_{7} & 0 & b_{8} & 0 & 0 & 0
\end{array}\right] \\
& \begin{array}{lllllllllllllllll}
0 & 0 & c_{3} & 0 & c_{4} & 0 & c_{5} & 0 & c_{6} & 0 & 0 & 0 & c_{7} & 0 & c_{8} & 0 & 0
\end{array} \\
& \begin{array}{lllllllllllllllll}
0 & 0 & 0 & 0 & 0 & 0 & 0 & 0 & 0 & 0 & 0 & 0 & 0 & 0 & 0 & 0 & 0
\end{array} \\
& \begin{array}{lllllllllllllllll}
0 & c_{3} & b_{3} & c_{4} & b_{4} & c_{5} & b_{5} & c_{6} & b_{6} & 0 & 0 & c_{7} & b_{7} & c_{8} & b_{8} & 0 & 0
\end{array} \\
& \begin{array}{lllllllllllllllll}
0 & 0 & 0 & 0 & 0 & 0 & 0 & 0 & 0 & l_{1} & 0 & 0 & 0 & 0 & 0 & l_{3} & 0
\end{array}
\end{aligned}
$$

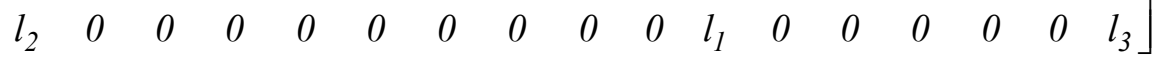


where

$$
\begin{aligned}
& a_{1}=\frac{\partial b_{1}}{\partial z}, \quad a_{2}=\frac{\partial b_{2}}{\partial z}, \quad a_{3}=\frac{\partial b_{3}}{\partial z}, \quad a_{4}=\frac{\partial b_{4}}{\partial z}, \quad a_{5}=\frac{\partial b_{5}}{\partial z}, \quad a_{6}=\frac{\partial b_{6}}{\partial z}, \\
& a_{7}=\frac{\partial b_{7}}{\partial z}, \quad a_{8}=\frac{\partial b_{8}}{\partial z}, \quad d_{1}=\frac{\partial l_{1}}{\partial z}, \quad d_{2}=\frac{\partial l_{2}}{\partial z}, \quad d_{3}=\frac{\partial l_{3}}{\partial z}, \quad e_{1}=\frac{\partial c_{1}}{\partial z}, \\
& e_{2}=\frac{\partial c_{2}}{\partial z}, \quad e_{3}=\frac{\partial c_{3}}{\partial z}, \quad e_{4}=\frac{\partial c_{4}}{\partial z}, \quad e_{5}=\frac{\partial c_{5}}{\partial z}, \quad e_{6}=\frac{\partial c_{6}}{\partial z}, \quad e_{7}=\frac{\partial c_{7}}{\partial z}, \quad e_{8}=\frac{\partial c_{8}}{\partial z} .
\end{aligned}
$$

\section{Nomenclature}

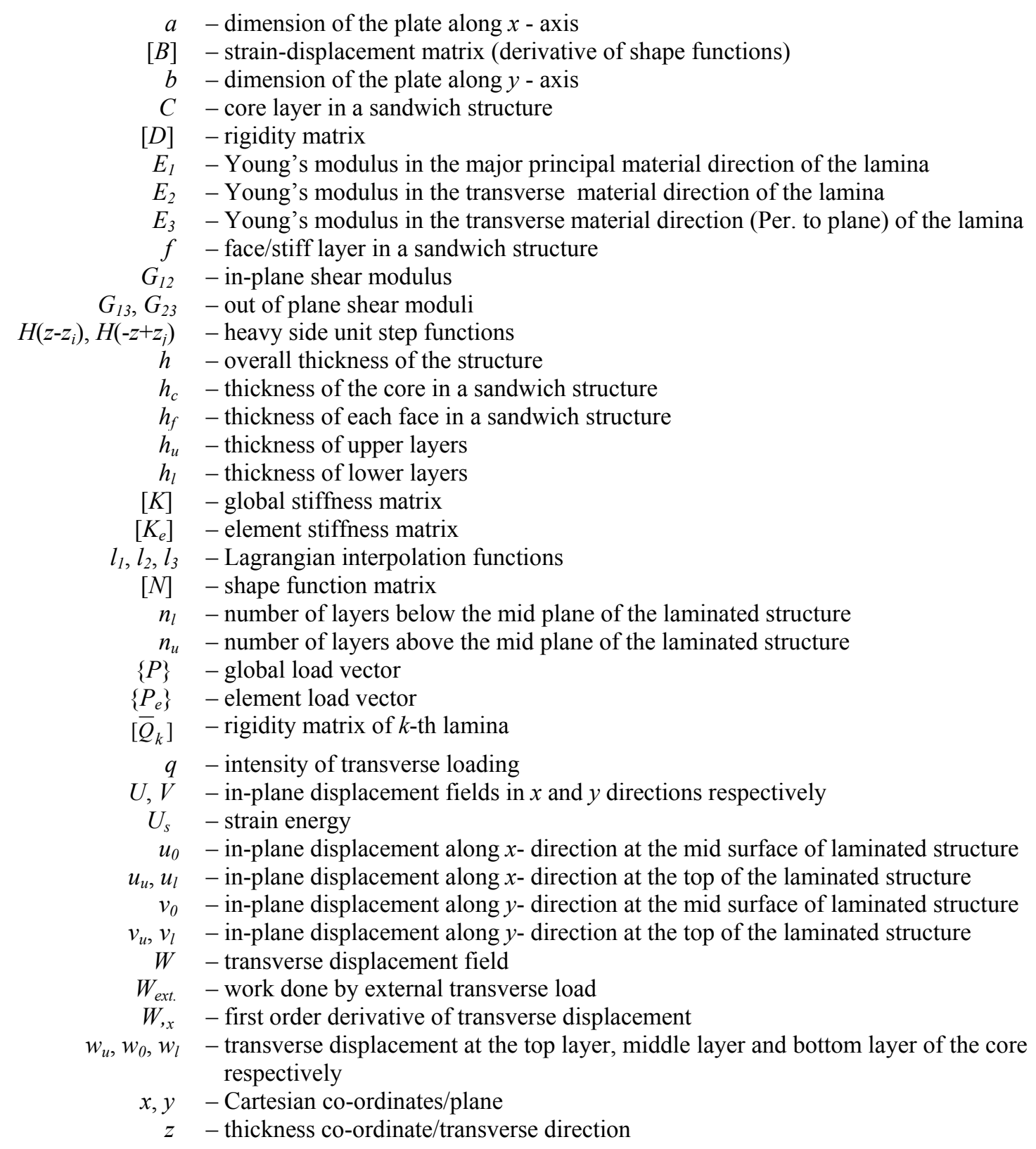




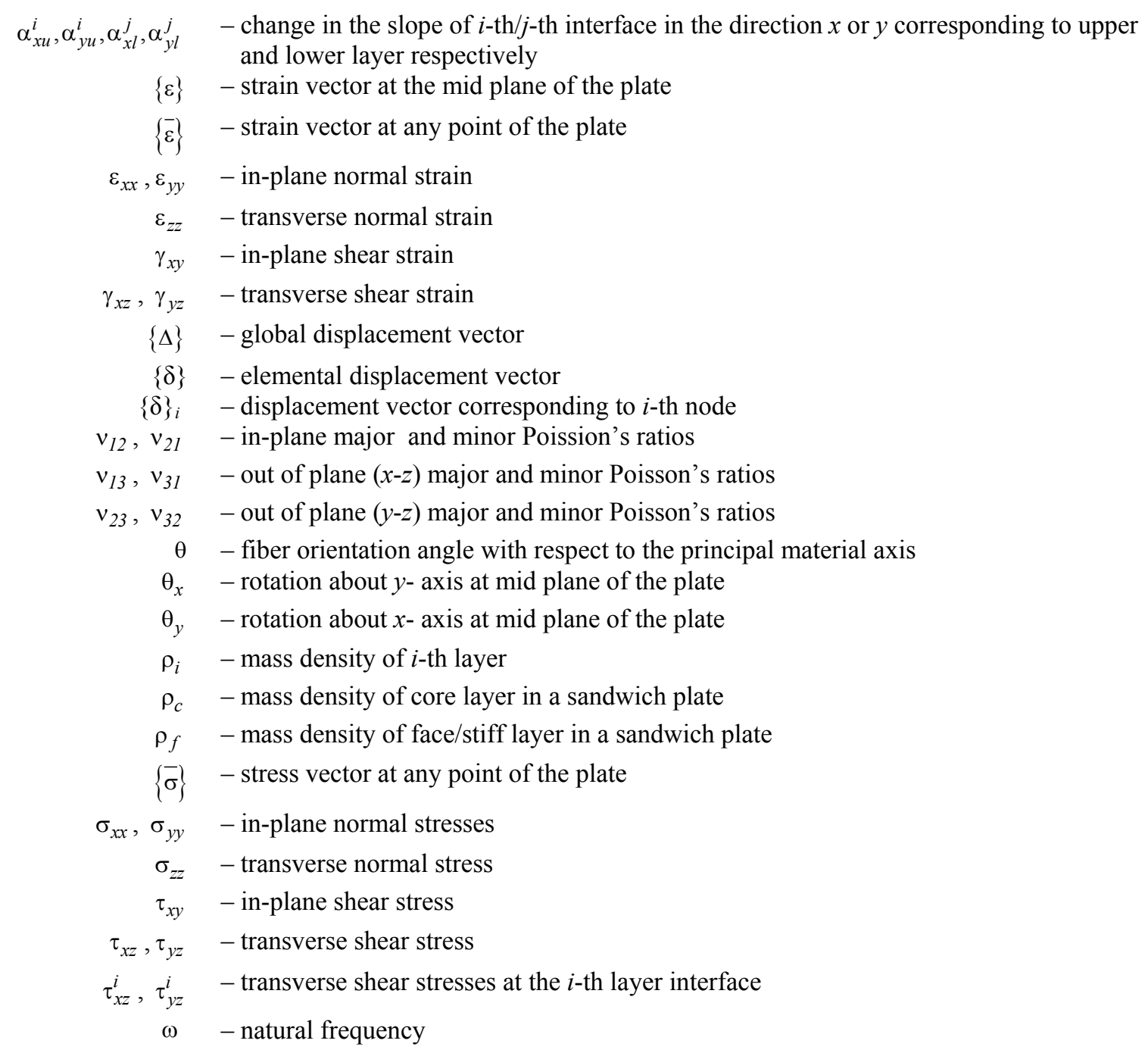

\section{Subscript}

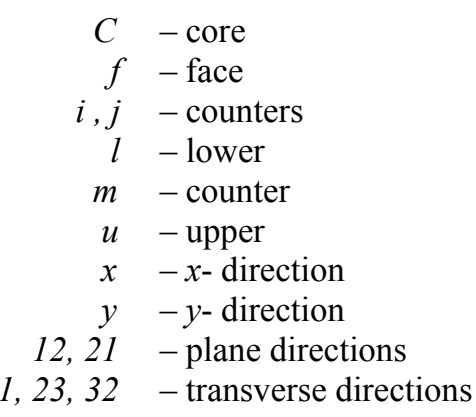

\section{Superscript}

$\begin{array}{ll}i & - \text { layer/interface } \\ j & - \text { layer/interface }\end{array}$ 


\section{References}

Averill R.C. (1994): Static and dynamic response of moderately thick laminated beams with damage. - Composites Engineering Journal, vol.4, pp.381-395.

Averill R.C. and Yip Y.C. (1996): Development of simple, robust finite elements based on refined theories for thick laminated beams. - Composite Structures, vol.59, pp.661-666.

Aitharaju V.R. and Averill R.C. (1999): $C^{0}$ Zigzag kinematic displacement models for the analysis of laminated composites. - Mech. of Comp. Mat. and Struct., vol.6, pp.31-56.

Aagaah M.R., Mahinfalah M. and Jazar G.N. (2003): Linear static analysis and finite element modeling for laminated composite plates using third order shear deformation theory. - Composite Structures, vol.62, pp.27-39.

Akhras G. and Li W. (2007): Spline finite strip analysis of composite plates based on higher order zigzag composite plate theory. - Composite Structures, vol.78, pp.112-118.

Aydogdu M. (2009): A new shear deformation theory for laminated composite plates. - Composite Structures, vol.89, pp.94-101.

Bhaskar K. and Varadan T.K. (1989): Refinement of higher order laminated plate theories. - AIAA J., vol.27, pp.1830-31.

Bambole A.N. and Desai Y.M. (2007): Hybrid-interface finite element for laminated composite and sandwich beams. Finite Element in Analysis and Design, vol.43, pp.1023-36.

Cho M. and Parmerter R.R. (1992): An efficient higher order plate theory for laminated composites. - Compos. Struct., vol.20, pp.113-23.

Cho M. and Parmerter R.R. (1993): Efficient higher order composite plate theory for general lamination configurations. - AIAA J., vol.31(7), pp.1299-1306.

Carrera E. (1996): $C^{0}$ Reissner-Mindlin multilayered plate element including zigzag and interlaminar stress continuity. - Int. J. for Numerical Methods in Engineering, vol.39, pp.1797-1820.

Cho Y.B. and Averill R.C. (1997): An improved theory and finite element model for laminated beams using first order zigzag sub-laminate approximations. - Composite Structure, vol.37, pp. 281-298.

Cho Y.B. and Averill R.C. (2000): First order zigzag sub-laminate plate theory and finite element model for laminated composite and sandwich panels. - Composite Structures, vol.50, pp. 1-15.

Carrera E. (2004): On the use of the Murakami's zig-zag function in the modeling of layered plates and shells. Compos. Struct., vol.82, pp.541-554.

Chakrabarti A. and Sheikh A.H. (2004): A new triangular element to model inter-laminar shear stress continuous plate theory. - Int. J. Num. Meth. Eng., vol.60, pp.1237-1257.

Chakrabarti A., Chalak H.D., Iqbal A. and Sheikh A.H. (2011): A new FE model based on higher order zigzag theory for the analysis of laminated sandwich beam with soft core. - Composite Structures, vol.93, pp.271-279.

Di Sciuva M. (1984): A refined transverse shear deformation theory for multilayered anisotropic plates. - Atti. Academia Scienze Torino, vol.118, pp.279-95.

Di Scuiva M. (1987): An improved shear deformation theory for moderately thick multilayered anisotropic shells and plates. - Journal of Applied Mechanics, vol.54, pp.589-596.

Di Scuiva M. (1992): Multilayered anisotropic plate models with continuous interlaminar stress. - Comput. Struct., vol.22(3), pp.149-67.

Di Sciuva M. (1993): A general quadrilateral multilayered plate element with continuous interlaminar stresses. Computer Structures, vol.47, pp.91-105.

Di Sciuva M. (1995): Development of anisotropic multilayered shear deformable rectangular plate element. Computer Structures, vol.21, pp.789-796.

Demasi L. (2005): Refined multilayered plate elements based on Murakami zig-zag functions. - Compos. Struct., vol.70, pp.308-316. 
Demasi L. (2009): Mixed plate theories based on generalized unified formulation Part IV: zig-zag theories. - Compos. Struct., vol.87, pp.195-205.

Demasi L. (2009): Mixed plate theories based on generalized unified formulation. - Part V: Results. - Compos. Struct., vol.88, pp.1-16.

Frosting Y. (2003): Classical and high order computational models in the analysis of modern sandwich panels. Composites: Part B, vol.34, pp.83-100.

Fares M.E. and Elmarghany M.K.H. (2008): A refined zigzag non-linear first order shear deformation theory of composite laminated plates. - Composite Structures, vol.82, pp.71-83.

Ferreira A.J.M., Roque C.M.C., Carrera E. and Cinefra M. (2011): Analysis of thick isotropic and cross ply laminated plates by radial basis function and a unified formulation. - Journal of Sound and Vibration, vol.330, pp.771-787.

Ferreira A.J.M., Roque C.M.C., Carrera E., Cinefra M. and Polit O. (2011): Radial basis functions collocation and a unified formulation for bending, vibration and buckling analysis of laminated plates, according to variation of Murakami's zigzag theory. - Eur. J. Mech., vol.30(4), pp.559-570.

Givil H.S., Rabinovitch O. and Frostig Y. (2007): High-order non-linear contact effects in the dynamic behavior of delaminated sandwich panel with a flexible core. - International Journal of Solids and Structures, vol.44, pp.77-99.

Goyal V.K. and Kapania R.K. (2007): A shear deformeable beam element for analysis of laminated composites. - Finite Element in Analysis and Design, vol.43, pp.463-477.

Icardi U. (2001): A three dimensional zigzag theory for analysis of thick laminated beams. - Composite Structures, vol.53, pp.123-135.

Icardi U. (2003): Applications of zigzag theories to sandwich beams. - Mechanics of Advanced Materials and Structures, vol.10, pp.77-97.

Kant T. (1982): Numerical analysis of thick plates. - Comp. Meth. Appl. Mech. Eng., vol.44(4), pp.1-18.

Kant T. and Swaminathan A. (2002): Analytical solutions for the static analysis of laminated composite and sandwich plates based on a higher order refined theory. - Composite Structures, vol.56, pp.329-344.

Kim J.S. and Cho M. (2005): Enhanced first-order shear deformation theory for laminated and sandwich plates. Journal of Applied Mechanics, vol.72, pp.809-817.

Kim J.S. and Cho M. (2006): Enhanced modeling of laminated and sandwich plates via strain energy transformation.Composites Science and Technology, vol.66, pp.1575-1587.

Kim J.S. and Cho M. (2007): Enhanced first-order theory based on mixed formulation and transverse normal effect. Int. J. of Solids and Struct., vol.44(3-4), pp.1256-1276.

Kulkarni S.D. and Kapuria S. (2007): A new discrete Kirchhoff quadrilateral element based on the third order theory for composite plates. - Computational Mechanics, vol.39, pp.237-246.

Kapuria S. and Kulkarni S.D. (2007): An improved discrete Kirchhoff element based on third order zigzag theory for static analysis of composite and sandwich plates. - Int. J. Num. Meth. Eng., vol.69, pp.1948-1981.

Khandelwal R.P., Chakrabarti A. and Bhargava P. (2012): An efficient FE model and least square error method for accurate calculation of transverse stresses in composites and sandwich laminates. - Composites: Part B. Accepted.

Lo K.H., Christensen R.M. and Wu E.M. (1977): A higher order theory of plate deformation, Part2. Laminated plates. - J. Appl. Mech. Trans. ASME, vol.44, pp.669-76.

Liou W.J. and Sun C.T. (1987): A three dimensional hybrid stress isoparametric element for analysis of laminated composite plates. - Computers and Structures, vol.25(2), pp.241-249.

Lee K.H., Senthilnathan N.R., Lim S.P. and Chow S.T. (1990): An improved zigzag model for the bending of laminated composite plates. - Composite Structures, vol.15, pp.137-148.

Lu X. and Liu D. (1992): An interlaminar shear stress continuity theory for both thin and thick laminates. - ASME Journal of Applied Mechanics, vol.59, pp.502-509.

Li X. and Liu D. (1995): Zigzag theory for composite laminates. - AIAA J., vol.33, No.6, pp.1163-65. 
Liu D. and Li X. (1996): An overall view of laminate theories based on displacement hypothesis. - J. Compos. Mater., vol.30, pp.1539-61.

Murakami H. (1986): Laminated composite plate theory with improved in-plane responses. - Journal of Applied Mechanics, vol.53, pp.661-666.

Manjunatha B.S. and Kant T. (1992): A comparison of nine and sixteen noded quadrilateral elements based on higher order laminate theories for estimation of transverse stresses. - J. Reinf. Plast. Compos., vol.11, pp.986-1002.

Pagano N.J. (1970): Exact solutions for rectangular bidirectional composites and sandwich plates. - Journal of Composite Materials, vol.4, pp.20-35.

Pervez T., Seibi A.C. and Al-Jahwari F.K.S. (2005): Analysis of thick orthotropic laminated composite plates based on higher order shear deformation theory. - Composite Structures, vol.71, pp.414-422.

Pandit M.K., Sheikh A.H. and Singh B.N. (2008): An improved higher order zigzag theory for the static analysis of laminated sandwich plate with soft-core. - Finite Element in Analysis and Design, vol.44, pp.602-10.

Pandit M.K., Sheikh A.H. and Singh B.N. (2008): Buckling of laminated sandwich plates with soft core based on an improved higher order zigzag theory. - Thin-Walled Structures, vol.46, pp.1183-1191.

Pandit M.K., Sheikh A.H. and Singh B.N. (2010): Stochastic perturbation based finite element for deflection statistics of soft core sandwich plate with random material properties. - Int. J. Mech. Sci., vol.51, No.5, pp.14-23.

Reissner E. (1944): On the theory of bending of elastic plates. - J. Math. Physics, vol.23, pp.184-191.

Reddy J.N. (1984): A simple higher-order theory for laminated composite plates. - J. Appl. Mech. Trans. ASME, vol.51, pp.745-52.

Reddy J.N. (1987): A generalization of two dimensional theories of laminated composite plates. - Commn. Appl. Numer. Meth., vol.3, pp.173-180.

Robbins D.H. and Reddy J.N. (1993): Modeling of thick composites using a layerwise laminate theory. - Int. J. Numer. Methods Eng., vol.36, pp.655-77.

Robbins D.H. and Reddy J.N. (1996): Theories and computational models for composite laminates. - Applied Mechanics Rev., vol.49, pp.155-199.

Rao M.K., Desai Y.M. and Chitnis M.R. (2001): Free vibrations of laminated beams using mixed theory. - Composite Structures, vol.52, pp.149-160.

Ramtekkar G.S. and Desai Y.M. (2002): Natural vibrations of laminated composite beams by using mixed finite element modeling. - Journal of Sound and Vib., vol.257(4), pp.635-651.

Ramtekkar G.S., Desai Y.M. and Shah A.H. (2003): Application of a three dimensional mixed finite element model to the flexure of sandwich plate. - Comput. and Struct., vol.81, pp.2383-2398.

Ramesh S.S., Wang C.M., Reddy J.N. and Ang K.K. (2009): A higher order plate element for the accurate prediction of interlaminar stresses in laminated composite plates. - Composite Structures, vol.91, pp.337-357.

Roque C.M.C., Cunha D., Shu C. and Ferreira A.J.M. (2011): A local radial basis functions- finite differences techniques for the analysis of composite plates. - Eng. Ana. Boun. Elem., vol.35, pp.363-374.

Rodrigues J.D., Roque C.M.C., Ferreira A.J.M., Carrera E. and Cinefra M. (2011): Radial basis functions collocation and a unified formulation for bending, vibration and buckling analysis of laminated plates, according to variation of Murakami's zigzag theory. - Composite Structures, vol.93(7), pp.1613-1620.

Sheikh A.H. and Chakrabarti A. (2003): A new plate bending element based on higher order shear deformation theory for the analysis of composite plates. - Fin. Elem. Anal. Des., vol.39(9), pp.883-903.

Sheikh A.H. and Chakrabarti A. (2003): A new Plate bending element based on higher order shear deformation theory for the analysis of composite plates. - Finite Element in Analysis and Design, vol.39, pp.883-903.

Singh S.K., Chakrabarti A., Bera P. and Sony J.S.D. (2011): An efficient $C^{0}$ FE model for the analysis of composites and sandwich laminates with general layup. - Lat. Ame. J. Sol. Struc., vol.8, pp.197-212.

Srinivas S. (1973): A refined analysis of composite laminates. - J. Sound Vibration, vol.30, pp.495-507. 
Toledano A. and Murakami H. (1987): A composite plate theory for arbitrary laminate configuration. - J. Appl. Mech., vol.54(1), pp.181-89.

Tu T.M., Thach L.N. and Quoc T.H. (2010): Finite element modeling for bending and vibration analysis of laminated and sandwich composite plates based on higher order theory. - Computational Material Science, vol.49, pp.390-394.

Vlachoutsis S. (1992): Shear correction factors for plates and shells. - Int. J. Num. Methods Eng., vol.33(7), pp.1537-52.

Wu Z., Chen R. and Chen W. (2005): Refined laminated plate element based on global local higher order shear deformation theory. - Composite Structures, vol.70, pp.135-152.

Wu Z., Lo S.H., Sze K.Y. and Chen W. (2012): A higher order finite element including transverse normal strain including for linear elastic composite plates with general lamination configurations. - Finite Element in Analysis and Design, vol.48, pp.1346-1357.

Yang P.C., Norris C.H. and Stavsky Y. (1996): Elastic wave propagation in heterogeneous plates. - Int. J. Solids Structure, vol.2, pp.665-84.

Yip Y.C. and Averill R.C. (1996): Thick beam theory and finite element model with zigzag sub-laminate approximations. - AIAA., vol.34, pp.1627-1632.

Zhen W., Wanji C. and Xiaohui R. (2010): An accurate higher-order theory and $C^{0}$ finite element for free vibration analysis of laminated composite and sandwich plates. - Compos. Struct., vol.92, pp.1299-1307.

Zhen W. and Wanji C. (2010): A $C^{0}$-type higher-order-theory for bending analysis of laminated composite and sandwich plates. - Compos. Struct., vol.92, pp.653-661.

Received: January 29, 2012

Revised: April 11, 2013 